See discussions, stats, and author profiles for this publication at: https://www.researchgate.net/publication/318206064

\title{
Profiling the Facial Comparison Practitioner in Australia
}

Technical Report · February 2017

\section{CITATION}

1

5 authors, including:

Veneta MacLeod

Australian Army Malaria Institute

5 PUBLICATIONS 36 CITATIONS

SEE PROFILE

2 Anna Ma-Wyatt

Q3 University of Adelaide

55 PUBLICATIONS 599 CITATIONS

SEE PROFILE

Some of the authors of this publication are also working on these related projects:

Unfamiliar face matching and response times View project

Gender Stereotypes and the Provocation Defence View project
READS

183

(29) Carolyn Anne Semmler

University of Adelaide

44 PUBLICATIONS 462 CITATIONS

SEE PROFILE 


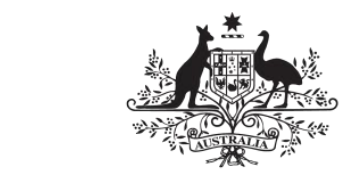

Australian Government

Department of Defence

Science and Technology

\title{
Profiling the Facial Comparison Practitioner in Australia
}

\author{
Rebecca Heyer, Veneta MacLeod, Laura Carter, Carolyn Semmler \& Anna \\ Ma-Wyatt
}

\section{National Security \& Intelligence Surveillance and Reconnaissance Division Defence Science and Technology Group}

\section{DST-Group-GD-XXXX}

\begin{abstract}
As part of a joint University of Adelaide-Defence Science and Technology Group project, known as the Human Operator Capability Project, a comprehensive survey of 149 facial comparison practitioners within Australian State and Federal Government agencies was conducted in late 2010. The survey collected data in a range of categories including: demographics, training and work history, facial comparison tools and techniques, attitudes to the facial comparison task and the use of facial recognition systems. This report outlines the key findings from the survey, including implications for the consideration of participating agencies at the time. An epilogue reflects on what has changed in the time since the survey was conducted.
\end{abstract}

\section{RELEASE LIMITATION}

Approved for public release. 


\section{UNCLASSIFIED}

Produced by

National Security \& Intelligence, Surveillance and Reconnaissance Division

DST Group Edinburgh

PO Box 1500

Edinburgh SA 5111

Telephone: 1300333362

(C) Commonwealth of Australia 2017

February 2017

Conditions of Release and Disposal

APPROVED FOR PUBLIC RELEASE 


\title{
Profiling the Facial Comparison Practitioner in Australia
}

\author{
Executive Summary
}

The types of tasks that facial comparison practitioners carry out, and the types of technology they have access to in order to verify the identity of individuals varies considerably across agencies within Australia. As part of a joint University of Adelaide-Defence Science and Technology Group project, known as the Human Operator Capability Project, a comprehensive survey of 149 facial comparison practitioners within Australian State and Federal Government agencies was conducted in late 2010. A draft copy of this report was circulated for comment to Steering Committee members of the Human Operator Capability Project in late 2010. Comments and suggestions made by the Committee were incorporated and the report was initially distributed as an unpublished document to participating agencies in early 2011. Since that time there have been numerous requests for the report, hence this belated publication to enable information sharing to a wider audience.

The survey results demonstrated that there was no single profile of a facial comparison practitioner in Australia. Facial comparison practitioners came from diverse backgrounds, having been exposed to different types of training and work experiences, and performed a range of different facial comparison tasks in a wide variety of environments. Despite this diversity, in terms of techniques employed and attitudes to facial comparison, they did have some commonalities. They tended to use the eyes, nose and ears more than other features for comparison and the majority rated themselves as 'accurate' to 'extremely accurate' at facial comparison tasks. They had good decision support, that is, they had access to a range of tools and techniques to perform their facial comparison duties, and were, for the most part, embedded in supportive teams that assisted their decision making. This level of decision support was pleasing given some aspects of ethnicity, ageing, image quality and appearance change could prove challenging while conducting facial comparisons.

Of those that were not currently using an automated facial recognition (FR) system, many would have liked the option to be able to use one to assist them in their duties. However, of those that were using an automated FR system, many appeared to be grappling with what the system could offer them. For many, FR systems were still very new and for some yet to be fully implemented in their agency. Training, generally speaking, was ad hoc, understanding of system functions was patchy, and usage was therefore not yet fully exploited. Almost everyone, though, saw the benefit of the FR system as both a decision and investigative support tool. Finally, almost all of the respondents reported that their facial comparison decision may be used as evidence in court (or as part of a larger investigation that may one day result in court proceedings). 
[DST-Group-GD-XXXX]

The survey results gave rise to a series of recommendations, including:

1. To update imagery within training sets, as well as training documentation for both new and refresher training.

2. To establish a networking and secondment program for facial comparison practitioners in Australia.

3. To encourage inter-agency training as both an information sharing and networking opportunity for facial comparison practitioners.

4. To encourage inter-agency decision aid sharing (including 1-page facial comparison guides such as The Six Key Tests and Facial Image Comparison - Quick Reference Guide).

5. To develop training programs that addresses all aspects of facial recognition systems (for those agencies currently employing such systems, or contemplating their introduction).

6. To consult facial comparison practitioners when:

a. developing new or refresher training packages

b. developing software/hardware acquisition or upgrade plans.

7. To consider the amendment of imagery standards to insist on ears being visible (where relevant).

8. To consider the possibility of future forensic requirements to determine the validity and reliability of facial comparison decisions.

The recommendations arising from the survey were generally accepted by all participating agencies and in the six years that have elapsed since the original report was disseminated, there have been significant changes in the field of facial comparison. Australia is now a key player on the world stage in terms of its contribution to the development of standards and best practice for facial comparison. The Australian government, via the committees and working groups established by the Attorney General's Department, has worked hard to coordinate activities in the facial comparison (and FR technology) space. In addition to the standards and best practice Australia has helped develop for the international facial comparison community (via involvement in International Standards Organisation (ISO) and Facial Identification Scientific Working Group (FISWG) activities, for instance), standards have been developed to guide the implementation of training and testing for facial comparison specialists here in Australia. Underpinned by these activities, Australia is leading the way in terms of progressing the field of facial comparison. 


\section{Contents}

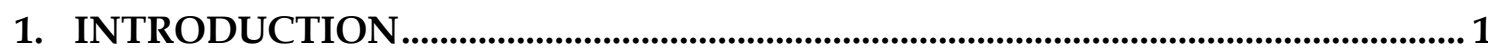

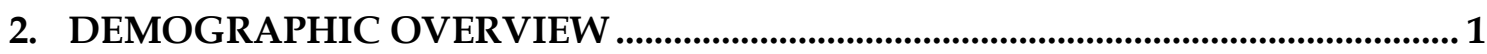

3. FACIAL COMPARISON TRAINING AND EXPERIENCE .................................... 2

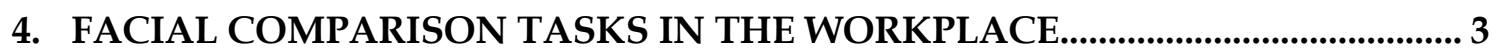

4.1 Types of Facial Comparison Tasks ..................................................................... 3

4.2 Percentage of Time Spent on Facial Comparison Tasks.....................................4

4.3 Number of Facial Comparison Decisions Per Day ..............................................4

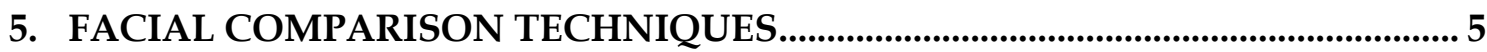

5.1 Facial Features Used for Comparison .........................................................................5

5.2 Other Features Used for Comparison …................................................................... 7

5.3 Self-reported Accuracy............................................................................................

6. FACIAL COMPARISON DECISION ASSISTANCE AND SUPPORT ..................... 8

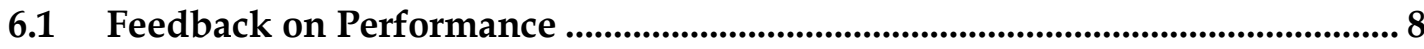

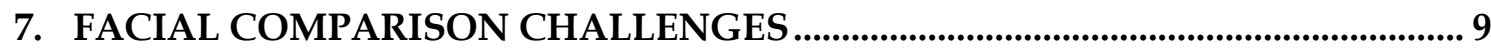

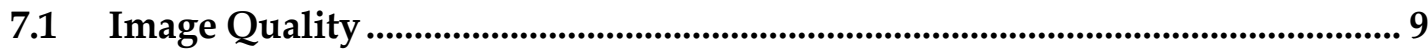

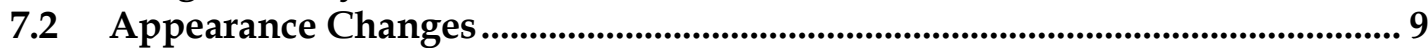

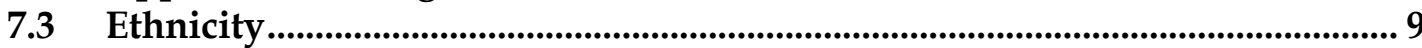

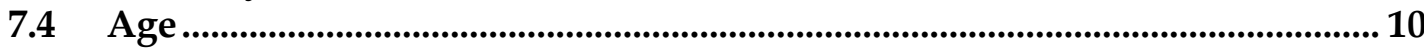

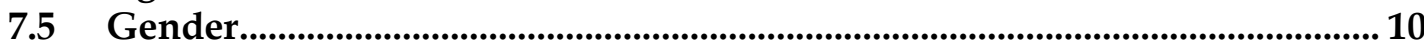

8. FUTURE DEVELOPMENT OF FACIAL COMPARISON SKILLS........................... 10

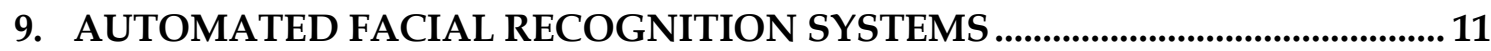

9.1 Facial Recognition System Decision Aids................................................ 12

9.2 Improving Facial Recognition Systems ........................................................... 13

10. REPORTING OF FACIAL COMPARISON DECISIONS......................................... 14

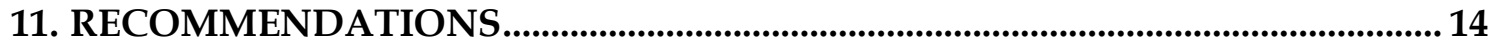

11.1 Updating Imagery Training Sets/Information for New and Refresher

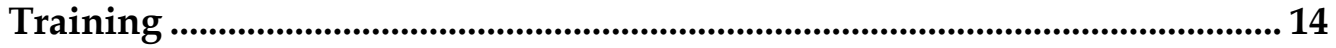

11.2 Networking and Secondment Program for Facial Comparison Practitioners .15 
[DST-Group-GD-XXXX]

11.3 Inter-Agency Training as Information Sharing and a Networking

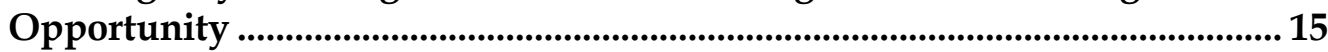

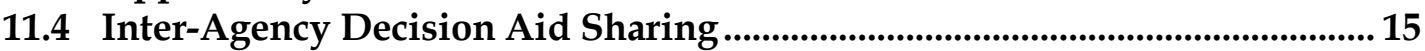

11.5 The Importance of Facial Recognition System Training................................ 15

11.6 Consultation of Facial Comparison Practitioners to Develop Training Packages and Develop Software/Hardware Acquisition/Upgrade Policy ... 16

11.7 Ear Visibility in Imagery .................................................................................. 16

11.8 Determination of the Validity and Reliability of Facial Comparison........... 16

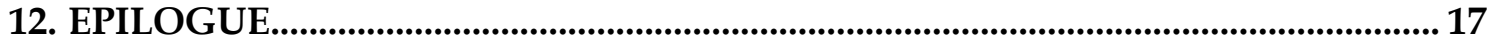

12.1 Reflecting on the Recommendations made in 2011....................................18

12.1.1 Imagery for Training and Development ......................................... 18

12.1.2 Networking and Secondment Programs........................................ 18

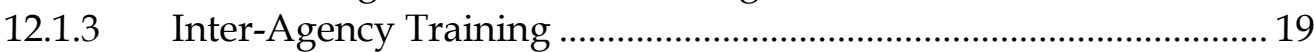

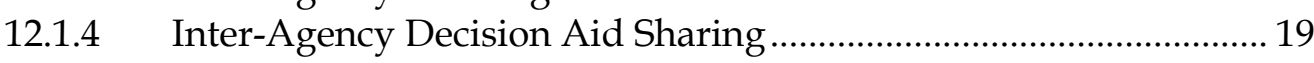

12.1.5 Facial Recognition System Training ............................................. 19

12.1.6 Consultation of Staff during Training, Policy or Technology

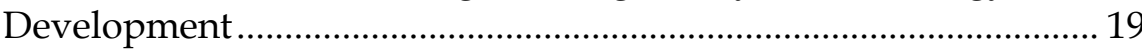

12.1.7 Imagery Standards and Ears ....................................................... 1920

12.1.8 Validity and Reliability ....................................................................... 20

12.2 The Future of Facial Comparison in Australia .................................................... 20

13. CONCLUSION

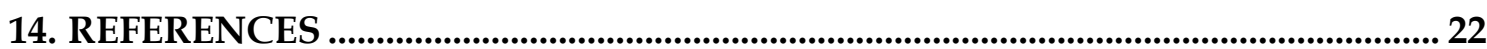

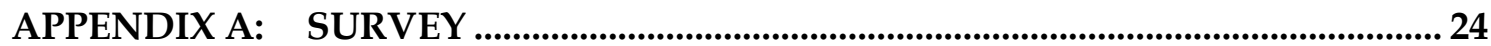




\section{Glossary}

$\begin{array}{ll}\text { CCTV } & \text { Closed circuit television } \\ \text { DNA } & \text { Deoxyribonucleic Acid } \\ \text { FaBCoE } & \text { Facial Biometrics Centre of Expertise } \\ \text { FACET } & \text { Facial Aptitude Competency Error Testing (Working Group) } \\ \text { FBI } & \text { Federal Bureau of Investigation } \\ \text { FISWG } & \text { Facial Identification Scientific Working Group } \\ \text { FR } & \text { Facial Recognition (Face Recognition) } \\ \text { ICAO } & \text { International Civil Aviation Organization } \\ \text { ISO } & \text { International Standards Organization } \\ \text { NIST } & \text { National Institute of Standards and Technology } \\ \text { OSAC } & \text { Organization of Scientific Area Committees } \\ \text { SWGSTAIN } & \text { Scientific Working Group on Bloodstain Pattern Analysis } \\ \text { TSWG } & \text { Training Standards Working Group } \\ \text { UFIG } & \text { Unfamiliar Face Identification Group } \\ \text { UK } & \text { United Kingdom } \\ \text { US } & \text { United States }\end{array}$





\section{Introduction}

The types of tasks that facial comparison practitioners carry out, and the types of technology they have access to in order to verify the identity of individuals varies considerably across agencies within Australia. As part of a joint University of Adelaide-Defence Science and Technology Group project, known as the Human Operator Capability Project ${ }^{1}$, a comprehensive survey of 149 facial comparison practitioners within Australian State and Federal Government agencies was conducted in late 2010. The Human Operator Capability Project Survey included questions regarding demographics, training and work history, facial comparison tools and techniques, attitudes to the facial comparison task and the use of facial recognition (FR) systems. Information collected through the survey was also used to inform the results of several empirical studies investigating a variety of facial comparison tasks (Calic, 2012; Heyer, 2013; Semmler,-Ma-Wyatt, Semmler, Heyer \& MacLeod, 2012).

A draft copy of this report was circulated for comment to Steering Committee members of the Human Operator Capability Project. Comments and suggestions made by the Committee were incorporated and the report was initially distributed as an unpublished document to participating agencies in early 2011. Since that time there have been numerous requests for the report, hence this belated publication to enable information sharing to a wider audience.

This report provides an overview of the main findings of the survey ${ }^{2}$ and includes implications for the consideration of participating agencies at the time. The paper concludes with an epilogue that reflects on what has changed since the survey was conducted, and the future of the facial comparison practitioner in Australia.

\section{Demographic Overview}

The survey was administered as part of the Human Operator Capability Project's Phase 2 Data Collection. During this time, 183 surveys were completed (81 males and 101 females with a mean age of 39.38 years responded). The respondents represented nine different Australian state and federal Government agencies.

While the main aim of the survey was to obtain further insight into the backgrounds, skills and opinions of facial comparison practitioners, 34 of the 183 respondents $(18.5 \%)$ were classified as untrained and/or inexperienced (i.e., not currently working in a facial comparison field, nor had they ever worked in a position where they had performed facial

\footnotetext{
1 This project (known officially as 'Improving Human Operator Capability for Face Biometric Identification and Recognition') was jointly funded by The Department of Prime Minister and Cabinet's Research Support for National Security Program (PR09-0078), as well as the University of Adelaide and DST Group. A human operator in this context referred to any person conducting facial comparison tasks (using images and/or a physically present person), with or without the assistance of a facial recognition system.

${ }^{2}$ It should be noted that the majority of respondents on the survey were from a single agency, accounting for just over half of all responses. Response numbers from other agencies were comparatively small. This potential bias should be kept in mind when interpreting data.
} 
comparison tasks; or they were new starters with less than 1 week of experience). For this reason, they either did not complete the majority of their surveys or their responses were not included in the analysis reported here.

\section{Facial Comparison Training and Experience}

Respondents were asked a series of questions about their educational backgrounds as well as their current and previous work experiences in the facial comparison or related area.

Of the 149 respondents who were deemed trained/experienced (the facial comparison practitioners), their educational backgrounds varied markedly both in terms of their level of education and the disciplines studied. The majority of respondents had completed secondary school (44\%) and some post-secondary education (55\%). The disciplines studied included: business, nursing, policing, international relations, massage, fitness and personal training, health sciences, psychology, economics, law, accounting, public policy, government, training and assessment, information management, photography, design, information technology, criminal justice, multimedia, science, linguistics, arts, teaching, music and finance.

Figure 1 outlines the respondent's duration of employment in a position in which they conduct facial comparison.

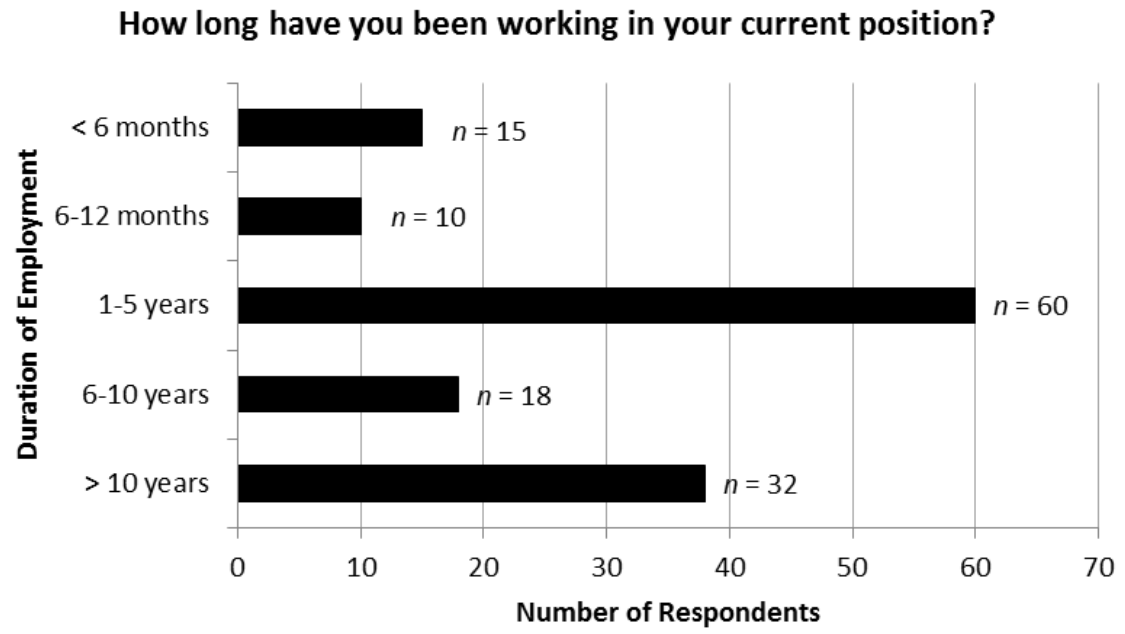

Figure 1 - Duration of Employment ${ }^{3}$

The majority (82\%) of facial comparison practitioners had been employed in their positions for at least one year.

\footnotetext{
${ }^{3}$ Note: eight respondents chose not to answer this question
} 
The survey results indicated that the majority of facial comparison practitioners reported on-the-job training/experience only (64\%), as opposed to any formal training in facial comparison. Formal training in facial comparison was limited, in most cases $(65 \%)$, to courses with duration of less than one day. Most of this training was reported to be selfdirected computer-based modules, which most respondents $(72 \%)$ rated as only ' moderately useful'.

\section{Facial Comparison Tasks in the Workplace}

Respondents were asked a series of questions designed to provide an indication of the types of facial comparison tasks they undertake and the amount of time they spend on such tasks.

\subsection{Types of Facial Comparison Tasks}

Respondents were first asked to indicate what types of facial comparison tasks they perform (with the option of nominating one or more types of tasks). The responses are shown in Figure 2.

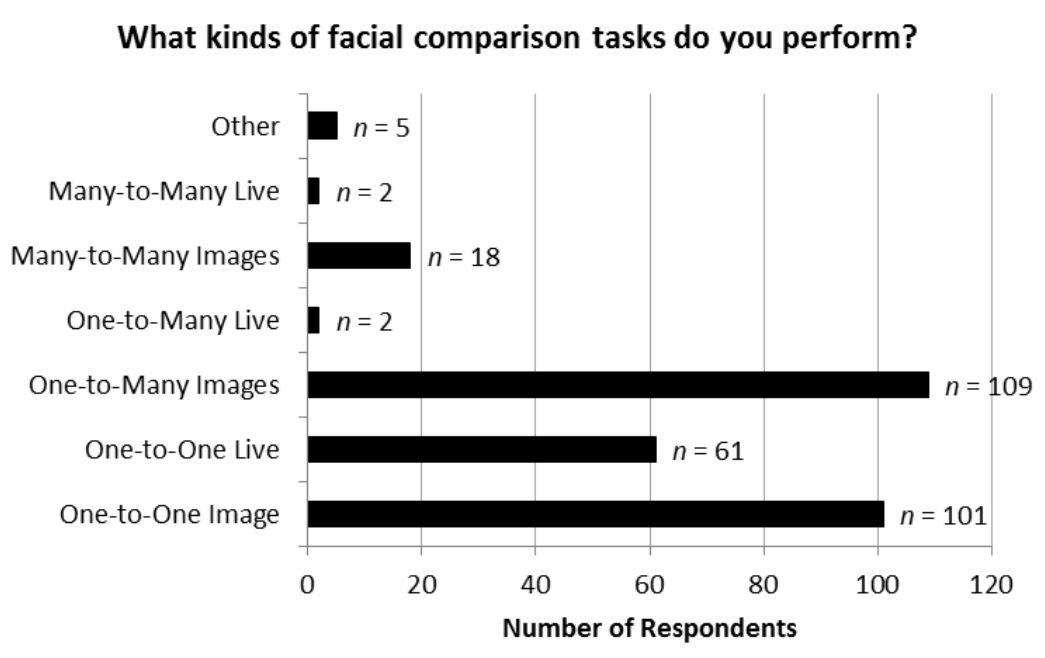

Figure 2 - The Types of Facial Comparison Tasks Performed

One-to-one image (comparing one image with another image) (68\%) and one-to-many image (comparing one image with many other images) $(73 \%)$ comparisons were the most common tasks performed, followed by one-to-one live (comparing an image with a live presentation of a person) (40\%). 
[DST-Group-GD-XXXX]

\subsection{Percentage of Time Spent on Facial Comparison Tasks}

Figure 3 provides an overview of the percentage of time respondents spend engaged in facial comparison tasks. Just over half of the respondents who answered the question $(52 \%)$ spent less than a third of their time on facial comparison.

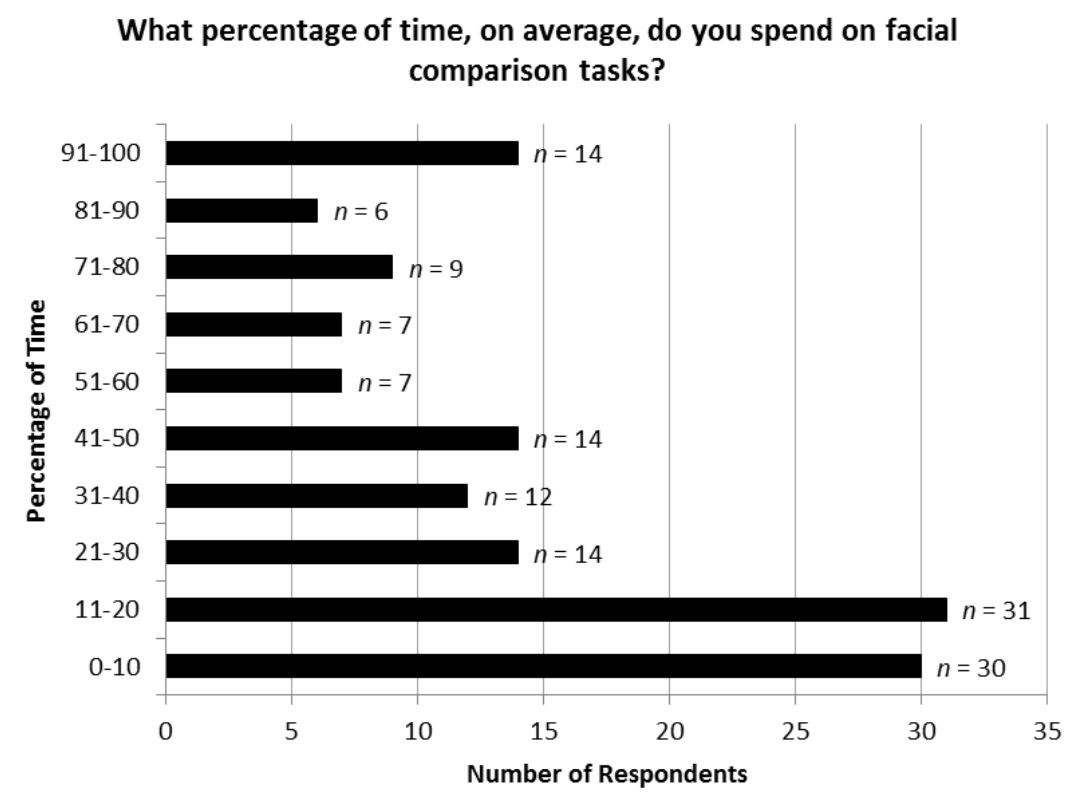

Figure 3 - Percentage of Time Spent on Facial Comparison Tasks 4

\subsection{Number of Facial Comparison Decisions per Day}

As shown in Figure 4, respondents were asked how many facial comparison decisions they make each day.

${ }^{4}$ Note: five respondents chose not to answer this question 


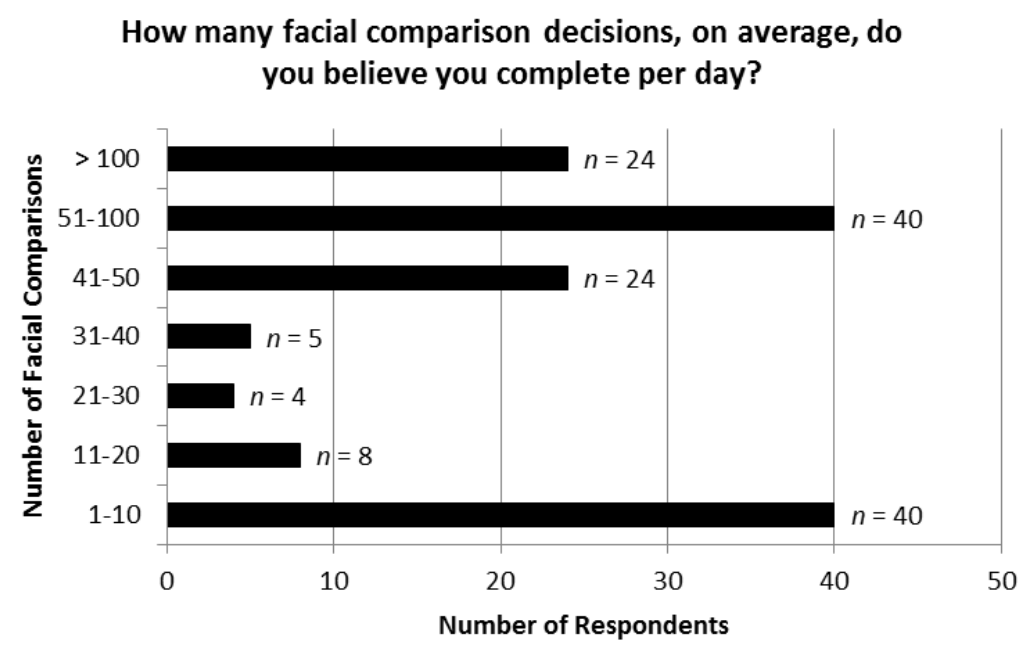

Figure 4 - Number of Facial Comparison Decisions Made Each Day5

Once again, responses varied, with respondents clustered in the ' $1-10$ ' decisions per day (generally investigations-related) (28\%) and '41-50' (17\%), '51-100' (28\%) and 'Greater than 100 ’ decisions $(17 \%)$ per day groups (generally processing-related).

\section{Facial Comparison Techniques}

Respondents were asked a series of questions about the techniques they use when making a facial comparison decision.

\subsection{Facial Features Used for Comparison}

Respondents were asked to indicate which areas of the face they used to make a comparison decision. To do this, they were provided with a face and asked to mark in order of use the areas they most commonly used. The facial features (type and frequency) used by respondents when making facial comparison decisions are shown in Figure 5.

${ }^{5}$ Note: four respondents chose not to answer this question 
Which facial features do you most commonly use when performing facial comparison tasks?

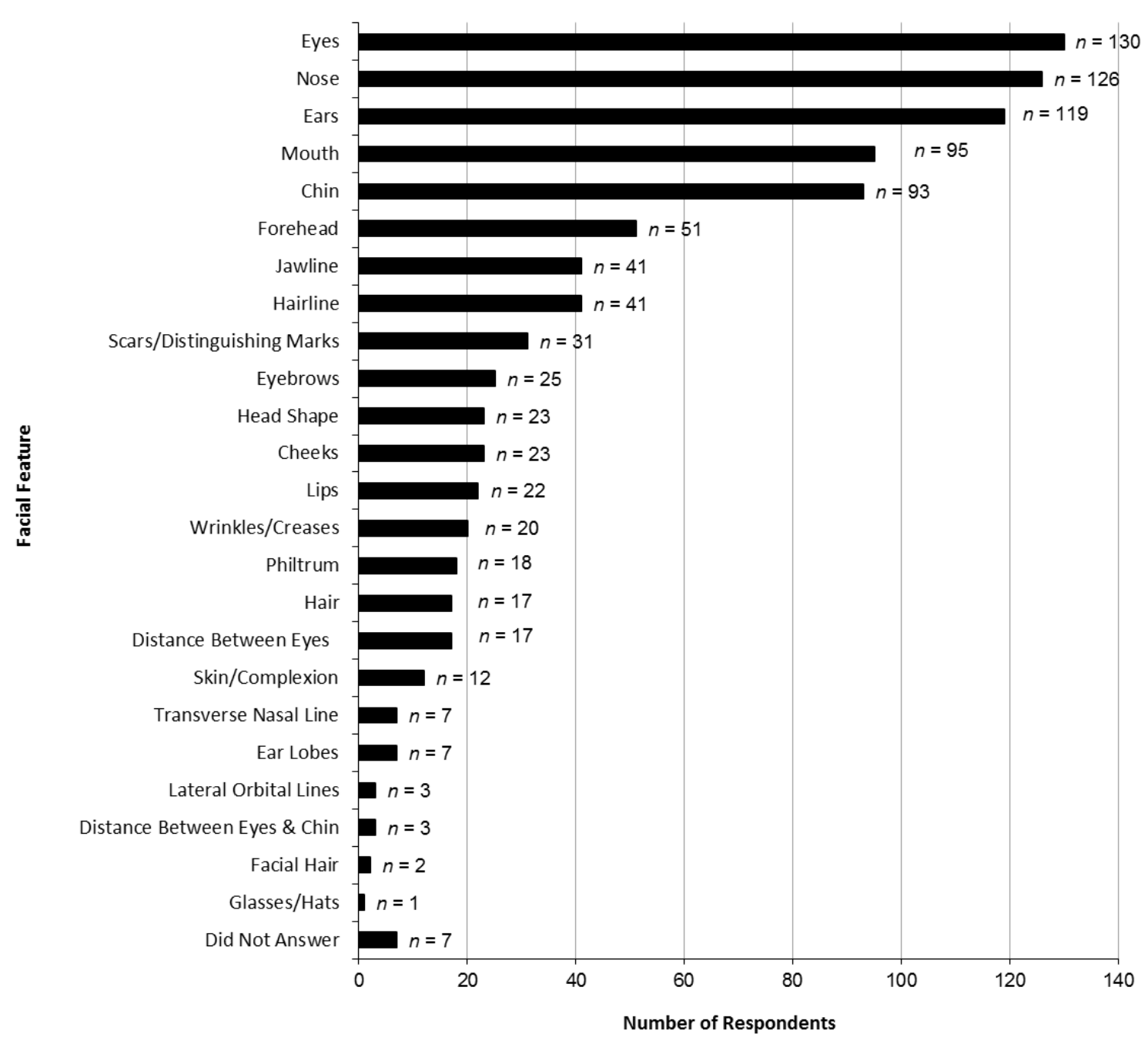

Figure 5 - Facial Features Commonly Used to Make Comparison Decisions ${ }^{6}$

The eyes $(87 \%)$, nose $(85 \%)$ and ears $(81 \%)$ were rated as the most popular features used in making a decision. In terms of feature order, almost $60 \%$ of facial comparison practitioners ranked the eyes as the feature they first focused on when making a facial comparison decision. The ears were cited as the next most common feature, with just over $17 \%$ of the respondents reporting that they used the ears first when making a facial comparison decision. This was an interesting finding given that ears are not always visible. Other features that respondents reported that they looked at first included the forehead $(34 \%)$, mouth $(81 \%)$, distance between eyes $(11 \%)$, jawline (28\%) and distinguishing marks $(21 \%)$.

\footnotetext{
${ }^{6}$ Note: seven respondents chose not to answer this question
} 


\subsection{Other Features Used for Comparison}

Respondents were asked to rate the usefulness of a range of other features. These results are presented in Figure 6.

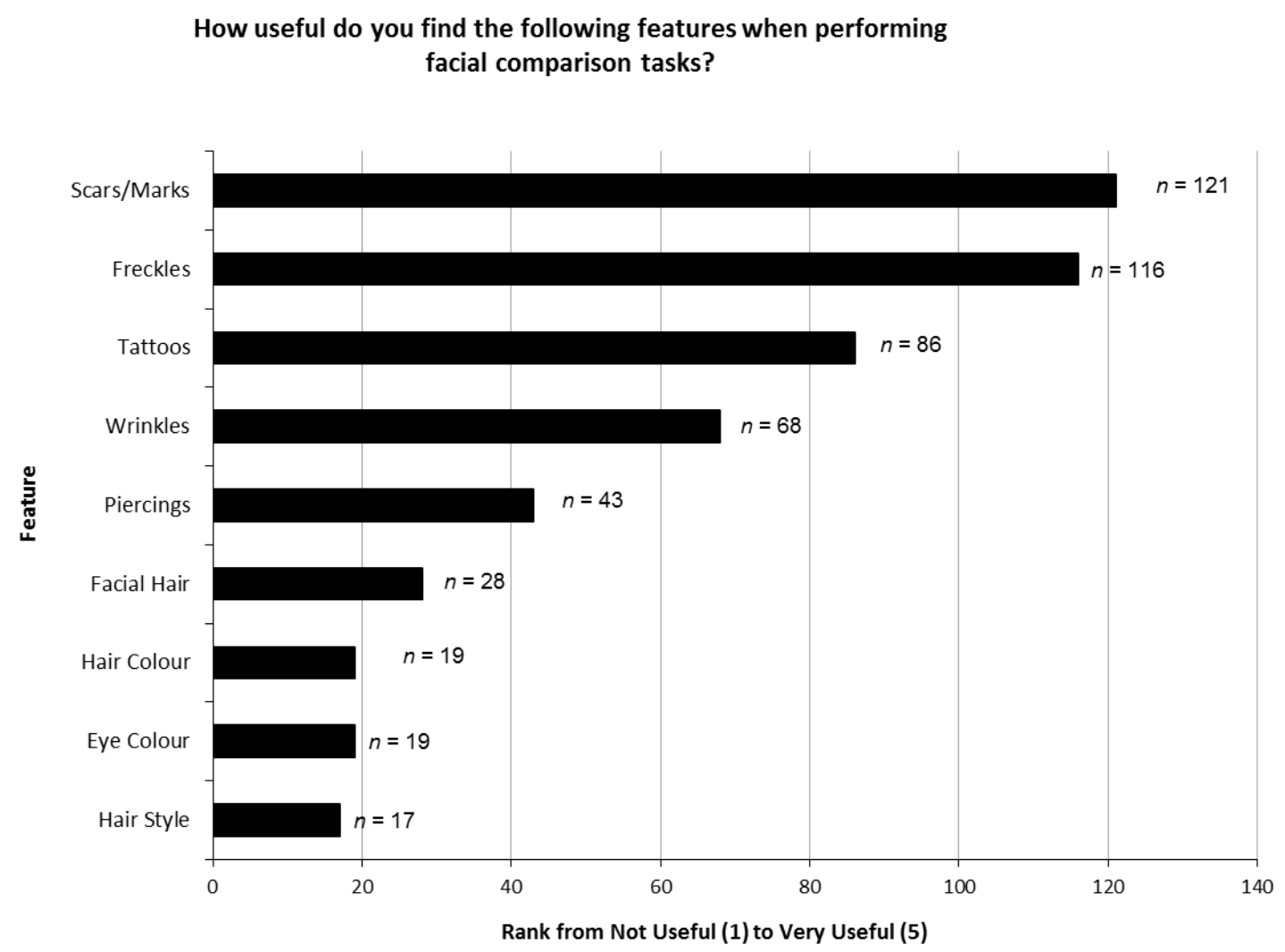

Figure 6 - Other Features Important in Making Facial Comparison Decisions

Scars/marks $(82 \%)$, freckles $(80 \%)$ and tattoos $(59 \%)$, which are relatively stable facial characteristics, were the most commonly rated as 'useful' to 'very useful', while less stable features, such as hair colour (13\%) and style (12\%), were rated as 'less useful' when making facial comparison decisions.

\subsection{Self-reported Accuracy}

Respondents were asked how accurate they thought they were at facial comparison. Just over $80 \%$ of the facial comparison practitioners surveyed rated themselves as either 'accurate' to 'extremely accurate' at their facial comparison tasks. 


\section{Facial Comparison Decision Assistance and Support}

Respondents were asked about the support and assistance (e.g., computer-based support, staff support, decision aids and other tools) they have available to them when they complete their facial comparison tasks. Figure 7 provides an overview of responses.

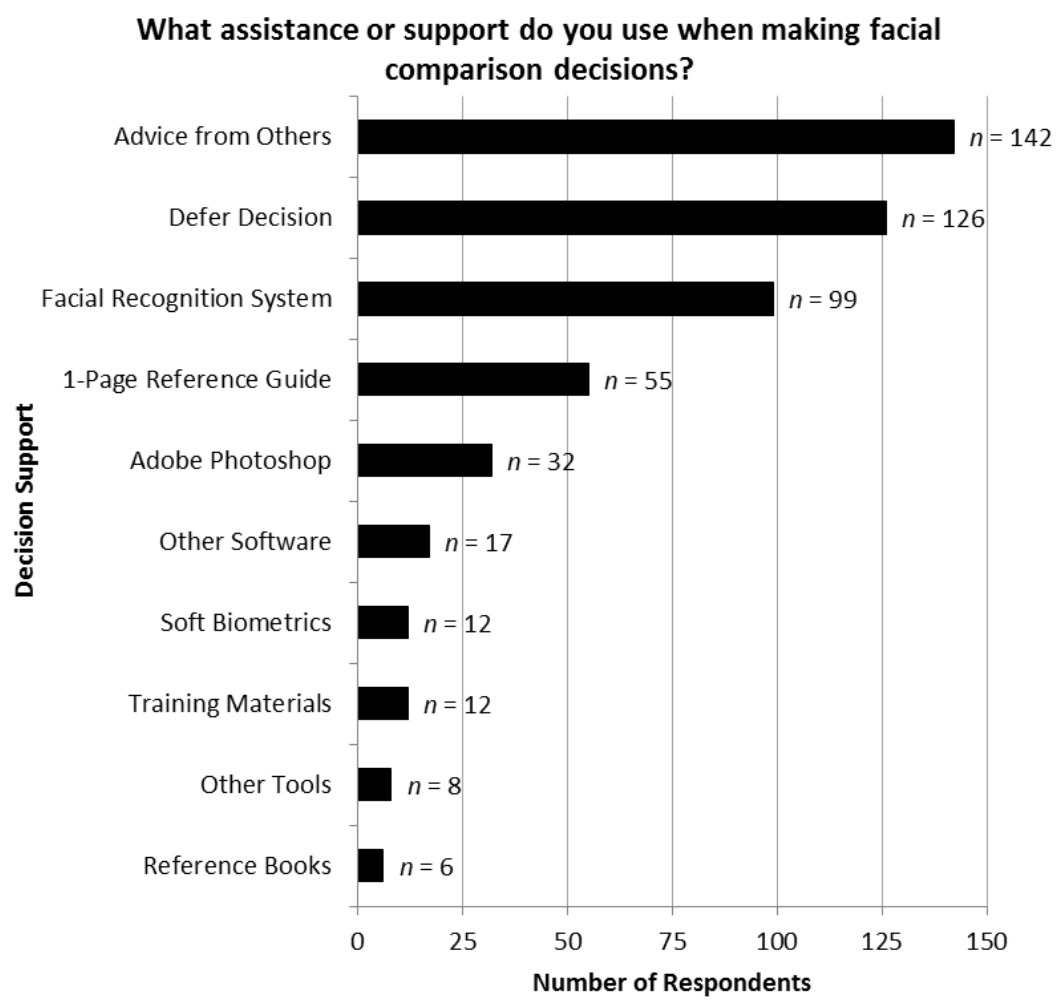

Figure 7 - Decision Support Mechanisms and Tools

In general, respondents from all agencies reported good decision support. If unsure about a decision they made use of a range of decision aids to assist them in their decision making, including seeking advice from others (95\%), FR systems (66\%), reference guides (37\%), training materials $(8 \%)$ and reference books $(4 \%)$. The ability to defer a decision was also popular (85\%). Aside from FR systems (to be discussed in Section 9), Adobe Photoshop $(22 \%)$ was the software tool most commonly used by respondents to assist them in making facial comparison decisions (with zooming/enlargement and side-by-side inspection reported as the most common image manipulation techniques employed while using Photoshop).

\subsection{Feedback on Performance}

Respondents were asked whether they receive feedback on their performance. Respondents were split, with $38 \%$ saying 'yes', $40 \%$ saying 'no' and the remainder 'unsure' or not answering. It was reported that feedback, when given, was generally provided as part of a 
quality assurance or performance management process, with some respondents reporting that they only received feedback when a mistake was made.

\section{Facial Comparison Challenges}

A series of questions was asked about the factors that can present a challenge to facial comparison. Specifically, the impact of image quality, appearance changes, ethnicity, age and gender was assessed.

\subsection{Image Quality}

Poor quality imagery is known to have a negative impact on human facial comparison ability for unfamiliar faces (Burton, Wilson, Cowan \& Bruce, 1999). The majority (around $85 \%$ ) of respondents also agreed, citing the following issues as most challenging:

- poor quality CCTV footage,

- black and white images,

- old images,

- blurry or out of focus images,

- pixelated digital passport images,

- off centre images, and

- images where ears are obscured.

\subsection{Appearance Changes}

Just over $60 \%$ of respondents indicated that changes in appearance between two images being used to make a facial comparison decision, or between an image and a live presentation of a person, can have a negative impact on their decision making. The most common problematic appearance changes cited included:

- changes in weight (both weight loss and weight gain),

- ageing (infant photos, elderly, adult images spanning greater than 10 years),

- cosmetic surgery,

- facial hair,

- glasses, and

- head coverings (such as hats or religious dress, particularly those that cover the ears). Although not strictly an appearance change, several respondents also commented on the difficulties they had experienced with similarities between siblings and other family members.

\subsection{Ethnicity}

Research has shown that people are generally better at identifying faces from their own race or ethnic background, and can have difficulty with other races, which is known as the ownrace bias (Byatt \& Rhodes, 2004). Just under $50 \%$ of respondents indicated that comparison of other ethnicities was often a challenge, and can have a negative impact on their 
comparison abilities. Although optional to provide specific examples, the most challenging ethnicities were classified as:

- Asians (indicated by 32 participants), and

- Africans (including Somali, Ethiopian and Sudanese, indicated by 29 participants).

Some respondents reported having to turn to second, third and fourth opinions to complete the task when faced with individuals from different ethnicities.

\subsection{Age}

Previous research has also indicated some support for an own-age bias, suggesting that people are better at identifying faces from their own age group as opposed to others (Anastasi \& Rhodes, 2006). However, 78\% of respondents on this survey did not feel that age made a difference to their facial comparison ability and $10 \%$ believed age differences made comparison easier. That being said, $12 \%$ of respondents did cite a negative impact of age, citing the following as the most challenging:

- children (particularly having to compare a baby photo with a toddler image),

- the elderly, and

- any task where the two images being compared were separated by a significant time period (generally greater than 10 years for an adult or a 2-5 year age gap for young children).

It should be noted that ageing was also mentioned in relation to appearance changes (as discussed above in Section 7.2). That is, while some respondents chose to rate ageing as having nil impact on their facial comparison ability, they then rated appearance changes as a result of ageing as having a negative impact. Thus the figure of $12 \%$ may be an underestimation.

\subsection{Gender}

Although previous research has shown some support for an own-gender bias, which posits that females are generally better at identifying females than males, and vice versa (Wright \& Sladden, 2003), gender did not appear to be an issue for the respondents of this survey. An overwhelming $92 \%$ of respondents reported that gender had no impact on their comparison ability, with $7 \%$ reporting that they were actually better at identifying the opposite gender and $1 \%$ citing they found it more difficult.

\section{Future Development of Facial Comparison Skills}

Respondents were asked what resources might help them to improve their facial comparison skills. Figure 8 outlines the responses. 


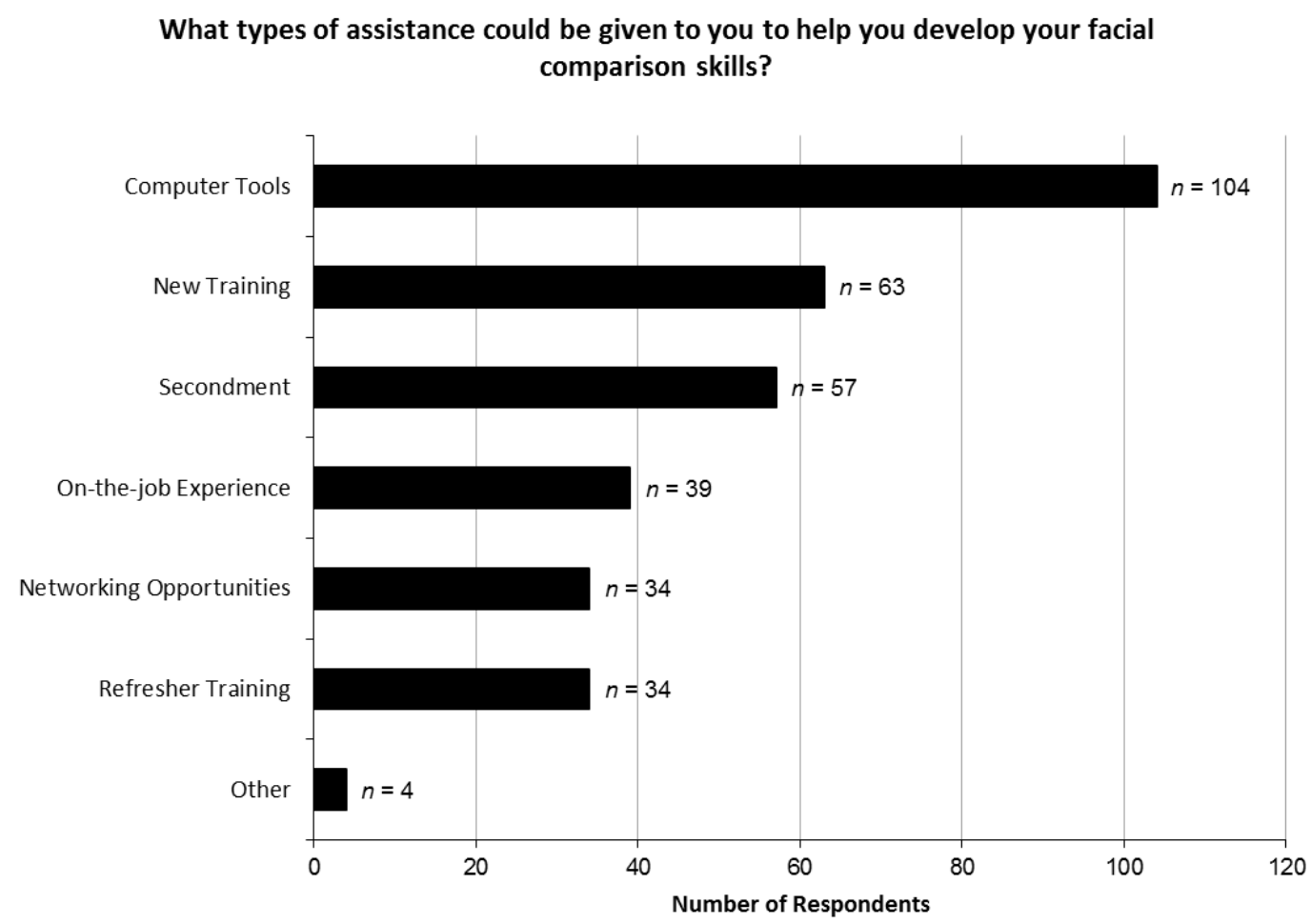

Figure 8 - Activities/Tools to Assist in Development

Computer tools (requested by $70 \%$ of all respondents) was the most popular response to this question with respondents simply wanting a larger toolbox available to them to help assist them to make facial comparisons. Overlay and facial mapping tools 7 , as well as automated FR systems, for those who were not currently using them, were frequently mentioned. Additionally, just over half of all respondents (53\%) mentioned they would like some further training (new and/or refresher), with several respondents suggesting that more images to practice with, as well as case studies, would be useful. Secondments to agencies engaged in similar work (38\%), as well as networking opportunities (23\%) with others working in a similar field were also mentioned as potentially useful developmental tools by respondents.

\section{Automated Facial Recognition Systems}

Respondents were asked a series of questions about FR systems, designed to ascertain how many agencies are using FR systems, in what ways they are being used, and in what ways their use may be improved. Of the 146 facial comparison practitioners that answered this set of questions, 99 respondents $(68 \%)$ indicated that they currently have access to a FR system and, of those, $58 \%$ use it 'all the time'. Training appeared ad hoc, with many

7 Note that overlay and facial mapping tools should be used with caution (see Edmond et al (2009) for more information). 
respondents reporting they had not been formally trained; instead briefings and on-the-job familiarisation were the most common way to learn their way around the system. Others had been trained to use the system, but had little understanding about how the system worked or its full capability.

Of those respondents currently using a FR system, 73\% reported that their system provides a candidate list of around 7-10 images to assist them in their decision making, although 19\% reported candidate lists of over 50 images and the remainder reported variable candidate list sizes (in some cases operators reported the ability to be able to set the candidate list size themselves). Of the 50 respondents who did not use a FR system for their duties, $37(74 \%)$ reported that they would like the opportunity to be able to use one.

\subsection{Facial Recognition System Decision Aids}

Respondents that used a FR system were asked about the kinds of decision aids their FR system offered. Figure 9 outlines the types of aids on offer.

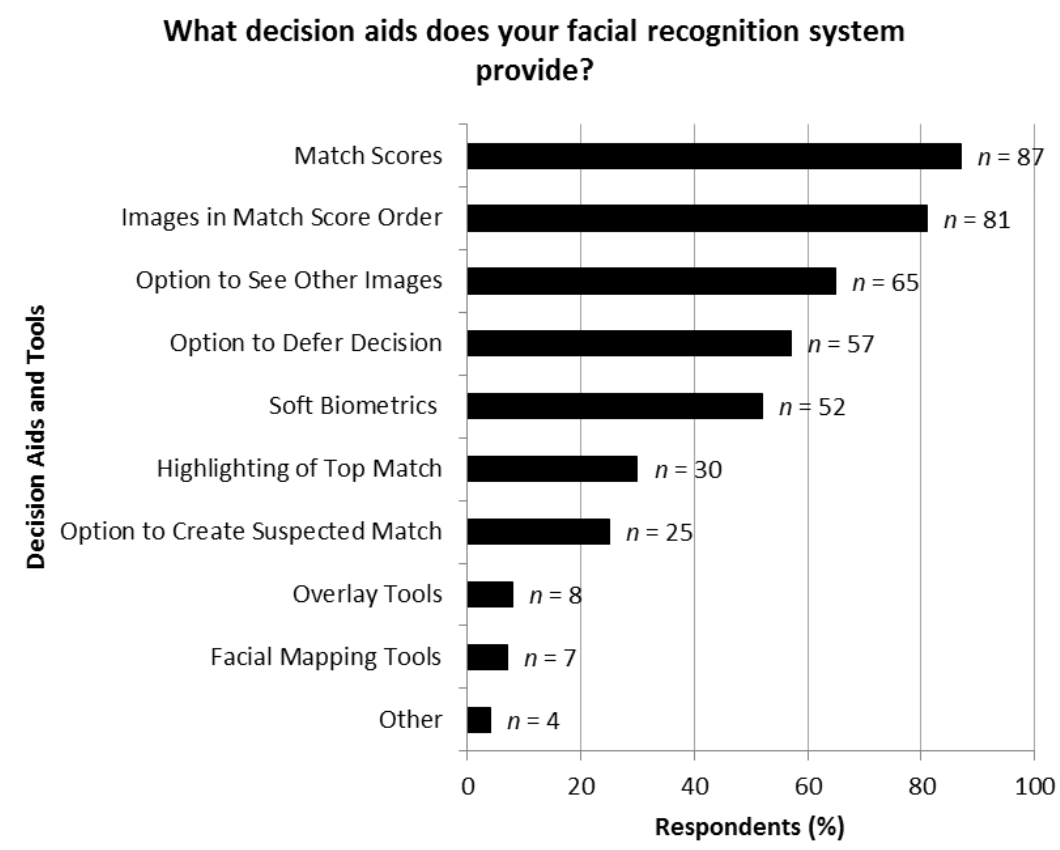

Figure 9 - Facial Recognition System Decision Aids ${ }^{8}$

Almost all (94\%) FR systems presented images with their associated match score visible (which might be a score out of 100, a statistic, or a percentage). The next most popular decision aid was to present images in match score order (87\%), followed by options to view other images $(70 \%)$ (e.g., the ability to retrieve other images of a person of interest from a database where multiple images exist). The 'other' decision aids that four respondents

\footnotetext{
8 Note: Six respondents chose not to answer this set of questions
} 
reported using included more sophisticated image comparison techniques (such as the ability to manipulate image characteristics and the ability to view image metadata). Interestingly, many respondents from the same agency (using the same system) answered the decision aids question very differently.

Respondents were asked to rate the usefulness of the decision aids their system provides. Of the 65 respondents who reported having the option to view other images in the course of their decision making, 97\% rated this as a 'useful' to 'very useful' tool. Other useful tools reported by respondents included highlighting top matches $(90 \%)$, the option to defer decisions $(90 \%)$, presenting images with their match scores $(87 \%)$, while just over $82 \%$ of respondents whose FR system presented images in match score order agreed this was also useful.

In terms of visual display, $86 \%$ of respondents were happy with the size of the screen with which they work (with the majority being 19-22 inch screens). However, some respondents reported that they would like the images to be larger; complaining that too much other information clutters their screens.

\subsection{Improving Facial Recognition Systems}

Responses to the FR set of survey questions suggested that human operators of the same system appeared to have a very different understanding of their system, in terms of its functions, usage and development, which may be a reflection of the lack of coordinated training that had been provided. Although that was the case, the majority of respondents believed their systems could be improved in some way. Suggested improvements to FR systems included:

- provision of video capability, to compare moving and still images,

- the ability to enlarge comparison images, to create a full screen sized one-to-one image comparison,

- the ability to improve imagery, e.g., contrast, filtering etc.,

- the addition of more sophisticated image comparison tools, e.g., image overlay and facial mapping tools,

- more sophisticated database filtering/binning, to assist in reducing the number of images searched on/to decrease search times,

- removal of duplicate images, which some respondents said often caused confusion during the decision making step, but with the option to introduce more images of a person of interest for comparison purposes if need be,

- larger gallery sizes,

- links to decision aids, training documentation and references to assist in decision making, and

- changing the format of the way images are displayed; however, no specific recommendations were made regarding how. 


\section{Reporting of Facial Comparison Decisions}

Respondents were asked a series of questions about the reporting of facial comparison decisions. These questions were asked in order to understand the different ways in which the participating agencies report their decisions. The results of the reporting questions suggest that reports are very much tailored to individual requirements/cases.

Formal electronic reporting was the most popular method of reporting the facial comparison decision (reported by 58\% of respondents). A typical report contained the person of interest's name and other identifying details and copies of images. Additionally, it sometimes included match scores, the process or methodology followed to arrive at the decision, as well as other agency-specific information (such as details about consultations, the decision aids used and/or the results of facial mapping exercises). Respondents indicated that reports were not necessarily formally verified, although when they were verified they tended to be cleared by someone at a higher/supervisory level.

Finally, 90\% of respondents agreed that their facial comparison decision could be used in some kind of legal proceedings.

\section{Recommendations}

The survey results gave rise to a series of recommendations, as follows.

\subsection{Updating Imagery Training Sets/Information for New and Refresher Training}

Agencies preparing training and development materials for new and/or refresher training may consider the inclusion of:

- Asian and African faces training set,

- infant, child and elderly (5-10 year age gap) training set,

- weight gain/loss before and after faces training set,

- cosmetic surgery before and after faces training set,

- with/without facial hair faces training set,

- with/without glasses faces training set,

- with/without head coverings training set (not necessarily ears-focussed),

- with/without ears visible training set,

- briefing/refresher regarding the dangers of relying on unstable facial characteristics to make facial comparison decisions, and

- briefings/refresher regarding the risks of using facial mapping or overlay tools to assist in decision making.

Agencies may also consider the use of a case study approach to training (this was mentioned as a useful training tool by some participants and something they would like more of). In addition, given that many respondents reported using training materials and 1-page facial 
comparison reference guides to assist them in their everyday work, such materials should be prepared with this later use in mind.

\subsection{Networking and Secondment Program for Facial Comparison Practitioners}

Respondents indicated that they were interested in more secondment and networking opportunities. Groups from other forensically-orientated disciplines have established a cohesive network in Australia under the auspices of the international Scientific Working Group's to which they belong. The Scientific Working Group on Bloodstain Pattern Analysis (SWGSTAIN) is one example (Reynolds \& Baldwin, 2010). The establishment of an Australian branch of the Facial Comparison Scientific Working Group (FISWG) ${ }^{9}$ may provide Australian facial comparison practitioners with a central 'meeting' place/networking opportunity with likeminded practitioners both here in Australia and internationally, as well as a mechanism through which a secondment program could be established.

\subsection{Inter-Agency Training as Information Sharing and a Networking Opportunity}

Agencies may consider (or continue, as is the case with some agencies) to offer places to other agencies on their training courses as an information sharing and networking opportunity. In particular, was recommended that there be mixed participation, so that participants from several agencies attend the one course, as opposed to a single agency attending one course offered by another agency, in order to maximise networking opportunities.

\subsection{Inter-Agency Decision Aid Sharing}

Agencies preparing training and development materials should continue to disseminate handouts/one-page reference guides to assist facial comparison practitioners in their decision making. The survey suggested that resources, such as the Department of Foreign Affairs and Trade's The Six Key Tests and the Department of Immigration and Border Protection's Facial Image Comparison - Quick Reference Guide are highly valued by Australian facial comparison practitioners. Agencies may consider inter-agency sharing of such resources.

\subsection{The Importance of Facial Recognition System Training}

The results of the FR system set of questions highlighted the variable understanding that human operators had of the system they use, but also the ad hoc nature in which much

\footnotetext{
${ }^{9}$ FISWG is the Facial Identification Scientific Working Group, established by the FBI. Its mission is to develop consensus standards, guidance and best practices for the discipline of facial identification. Several Australian agencies have representation on FISWG and representatives have attended the bi-annual meetings in the United States. Membership is open to facial identification practitioners, researchers and managers. For more information see: www.fiswg.org
} 
training and development appears to have been conducted. Australian agencies implementing FR systems should be careful not to neglect the training and development aspects of implementing a new system. The FISWG guidance on training states that all facial comparison practitioners should, at a minimum, "have a general knowledge of automated biometric systems. This includes, but is not limited to, user input and operation, system operation and output, and the limitations of the technology" (FISWG, 2010, p. 2).

\subsection{Consultation of Facial Comparison Practitioners to Develop Training Packages and Develop Software/Hardware Acquisition/Upgrade Policy}

Many useful comments and suggestions were recorded in the free text fields of the survey response forms.

In relation to training, just over half of the respondents reported that they would like new or refresher training to assist them in their development. A few respondents made suggestions about what they would like a training package to contain (e.g., more image practice and case studies). Agencies may, therefore, consider consulting their facial comparison practitioners for suggestions of what training they would like; and/or consult selected staff for their advice when contemplating changes to pre-existing training packages.

Software tools were the most popular type of assistance respondents wanted more of to assist them in their duties. In addition many respondents had valid suggestions about how to improve the user interfaces of the computer-based systems they use (see Section 9.2). Agencies may, therefore, consider consulting their facial comparison practitioners when developing software/hardware acquisition or upgrade plans for both their input and to explain why certain software tools may not be suitable (as may be the case with the most commonly requested tools, image overlay and facial mapping, both of which should be used with caution, as highlighted by Edmond et al, 2009).

\subsection{Ear Visibility in Imagery}

Ears are a key identifying feature, cited by $84 \%$ of respondents as an important part of their decision making, with almost $15 \%$ looking to the ears first when making a comparison decision. Respondents reported frustration when not being able to see ears, particularly given that many are trained to make comparison decisions using the ears. Agencies with control over imagery standards (e.g., passport/visa/license) may reconsider those standards with regards to ear visibility (i.e., requiring all applicants to place their hair behind their ears in photographs).

\subsection{Determination of the Validity and Reliability of Facial Comparison}

The majority of respondents $(90 \%)$ reported that their facial comparison decision could be used in legal proceedings of some description. While it is generally accepted that facial comparison is far from the 'gold standard' of DNA, the mere fact that comparison decisions can form part of a larger case means that they are open to scrutiny. Given the recent criticism of the lack of validation of forensic comparison methodologies, including facial comparison 
(Edmond, 2010), there is a requirement to develop methods for determining the validity and reliability of human facial comparison expertise. This may follow a similar model to fingerprint experts (Dror \& Rosenthal, 2008) and may be even more pertinent with the introduction of FR systems to assist facial comparison practitioners in making their decisions.

\section{Epilogue}

Six years have now elapsed since the original report was disseminated to participating agencies and considerable progress has been made in the development of the field of facial comparison both internationally and here in Australia.

Aside from the ISO/IEC SC 37 committee on biometrics, which has multiple Australian representatives from the FR technology community, Australia has also figured prominently in several international committees more focussed on the development of the field of facial comparison itself. The Facial Identification Scientific Working Group (FISWG), for instance, was established in 2009 by the Federal Bureau of Investigation (FBI) to develop standards, guidelines and best practice for facial image comparison (FISWG, 2009). There are many Australian government representatives actively involved in this group who regularly travel to meetings in the United States to contribute to the development of the field of facial comparison. In 2014, linked to FISWG, the Facial Identity Subcommittee was established under the Organization of Scientific Area Committees (OSAC), governed by the National Institute of Standards and Technology (NIST) in the United States. This committee also includes several Australian members and guests. The OSAC's aim is to "support the development and promulgation of forensic science consensus documentary standards and guidelines, and to ensure that a sufficient scientific basis exists for each discipline" (NIST, 2017). Australian representatives of the facial comparison community are also regularly invited to attend and present at a range of international meetings, such as the International Face Collaboration Meeting, a joint US/UK government initiative, and the UK Government Biometrics Working Group.

Here in Australia, the Attorney General's Department created the National Biometrics Interoperability Framework in 2012 to provide a set of principles to encourage collaboration between Australian government agencies using biometrics systems. Under this Framework the Facial Biometric Centre of Expertise (FaBCoE) was established (Australian Government 2015). The aim of FaBCoE is to implement the Biometrics Interoperability Framework, to discuss standards, capability development, information sharing and set best practice. Under FaBCoE two key working groups were established: the Training Standards Working Group (TWSG) in 2014 and the Facial Aptitude Competency \& Error Testing (FACET) working group in 2015. TSWG's role was to develop a comprehensive set of training standards for facial comparison practitioners across Australian Government (Moss, 2015). TSWG defined four key facial comparison professional roles: facial processor, facial reviewer, facial examiner and forensic facial examiner and for each role defined the minimum competencies (training and development) required. The FACET working group's aim was to define aptitude, competency, proficiency and error rate testing and set best practice standards for 
each of these across the four facial comparison roles (Moss, 2016). Work has recently begun (under $\mathrm{FaBCoE}$ ) to consider how best to implement the recommendations of both TSWG and the FACET working group, which should realise significant improvements in recruitment, training and development for the field of facial comparison in Australia.

Outside of government the field of facial comparison has also been bolstered by the research community. In 2013, for instance, the first meeting of the Unfamiliar Facial Identification Group (UFIG) was held at the University of New South Wales. The aim of UFIG is to bring together researchers from a range of universities and research organisations, practitioners from state and federal government agencies, FR technology vendors, and managers to share current research findings, discuss operational issues and highlight developments in the field. This group meets annually and has grown over the years to incorporate international keynote speakers. Since 2010, the field of facial comparison has also featured prominently in conference presentations by Australian researchers at the Australasian Experimental Psychology Conference, the International Symposium on the Forensic Sciences, Biometrics Institute Asia Pacific Conference, and the Society of Applied Research in Memory and Cognition International Conference. The number of journal publications by Australian authors has also increased and some have garnered international media attention (see White et al, 2014 and Connor, 2014, for an example).

\subsection{Reflecting on the Recommendations made in 2011}

To further demonstrate the developments of the last six years, it is useful to reflect on the recommendations made in 2011.

\subsubsection{Imagery for Training and Development}

All agencies acknowledged that this was a sensible recommendation and have been working towards developing repositories of appropriate ground truthed imagery for training and development purposes. The Department of Immigration and Border Protection, for example, maintain a number of sets of operational images used in training for pre and post training testing, as well as a set of operationally challenging imagery (siblings and twins, different age groups and ethnicities for example) for development among their facial reviewer and examiner staff. Access to operationally relevant, ground truthed imagery suitable for training and development use with a wider audience, however, remains a challenge.

\subsubsection{Networking and Secondment Programs}

Networking amongst facial comparison practitioners has increased since 2011. As previously stated, a number of practitioners, from a range of agencies, meet regularly via standards, training and testing committees, as well as interest groups and conferences. While formal inter-agency secondments have not yet been established, they remain a goal for some agencies. Larger agencies with multiple layers of expertise, however, have sought 
to use short-term secondments as a way of developing their staff, or identifying those appropriate to progress to higher levels of expertise.

\subsubsection{Inter-Agency Training}

This was another recommendation that was accepted and has been implemented across a range of agencies. The Department of Immigration and Border Protection, for instance, regularly provide training places to other government agencies and more recently the Australian Federal Police offered places to other government agencies on their specialist training. Although not strictly inter-agency training, the Canberra Institute of Technology began offering a Certificate IV in Biometrics in 2012, with a facial image comparison/FR major. The course, for both the general public and practitioner community, was designed with the input of several government agencies and is taught by representatives from select agencies (Canberra Institute of Technology, 2017). As Australia moves to implement the recommendations of the TSWG and the resulting Facial Training Standards document, it is likely that opportunities for inter-agency training will increase.

\subsubsection{Inter-Agency Decision Aid Sharing}

Again, this was a recommendation accepted by participating agencies and via the interagency training and networking now happening in the space decisions aids and other useful documentation continue to be shared.

\subsubsection{Facial Recognition System Training}

As previously mentioned, the TSWG established under FaBCoE has defined the competencies required for each individual facial comparison role. Training for all facial comparison roles in Australia now includes modules on FR systems - introduction to operation, standards, performance and limitations of the systems.

\subsubsection{Consultation of Staff during Training, Policy or Technology Development}

This was another recommendation that was accepted and as previously discussed several whole-of-government committees (e.g., FaBCoE, TSWG, FACET) have recently been established to discuss development across the facial comparison spectrum (from recruitment to training and development, to the technology itself). These committees now involve facial comparison practitioners in addition to managers, policy makers, and researchers. In terms of FR systems, due to the small team sizes of most agencies, the practitioners using the systems are invariably driving the acquisition and implementation of these systems as well, working closely with systems integrators to ensure a solution appropriate for their respective use cases (Tullberg \& Owens, 2016).

\subsubsection{Imagery Standards and Ears}

While Australia still complies with the International Civil Aviation Organization (ICAO) standard for passport image acquisition (ICAO, 2003), which makes no recommendations 
regarding ear visibility, some countries have recently amended their passport image standards to insist that ears are visible (e.g., Kenya High Commission, 2017).

\subsubsection{Validity and Reliability}

Validity and reliability is still a hot topic in the facial comparison area and recent high profile cases in Australian Law have reiterated the importance of the issue (Edmond et al, 2016). As previously mentioned, the FACET working group was established to address this very issue. A key outcome of the group was a document setting the standards for testing of facial comparison practitioners in Australia. Once these standards have been endorsed by FaBCoE, work will begin on the development of tests for measuring aptitude, competency, proficiency and error rates among facial comparison practitioners.

\subsection{The Future of Facial Comparison in Australia}

The field of facial comparison in Australia has come a long way since the Human Operator Capability Survey was administered in 2010. Once the standards for training and testing have been endorsed by $\mathrm{FaBCoE}$, it is expected that attention will turn to developing and implementing the training courses and tests across all government agencies employing facial comparison practitioners. In doing so, Australia will become the first country in the world to have implemented a set of nationally accepted training competencies and testing regimes for facial comparison.

\section{Conclusion}

The Human Operator Capability Survey was the first of its kind in the world and demonstrated that there was no single profile of a facial comparison practitioner in Australia. Facial comparison practitioners come from diverse backgrounds, have been exposed to different types of training and work experiences, and perform a range of different facial comparison tasks in a wide variety of environments. Despite this diversity, in terms of techniques employed and attitudes to facial comparison, they did have some commonalities. They tended to use the eyes, nose and ears more than other features for comparison and the majority rated themselves as 'accurate' to 'extremely accurate' at facial comparison tasks. They had good decision support and were, for the most part, embedded in supportive teams that assisted their decision making. This level of decision support was pleasing as they reported some aspects of ethnicity, ageing, image quality and appearance change to be challenging when conducting facial comparisons. At the time of the survey, those respondents that were using an automated FR system appeared to be grappling with what the system could offer them. For many, FR systems were still yet to be fully implemented in their agency. Training, generally speaking, had been ad hoc, understanding of system functions was patchy, and usage was therefore not yet fully exploited.

The recommendations arising from the survey were generally accepted by all participating agencies and in the six years that have elapsed since the original report was disseminated, there have been significant changes in the field of facial comparison. Australia is now a key player on the world stage in terms of its contribution to the development of standards and 
best practice for facial comparison. The Australian government, via the establishment of whole-of-government committees and working groups, has worked hard to coordinate activities in the facial comparison (and FR technology) space. In addition to the standards and best practice Australia has helped develop for the international facial comparison community, Australia now has its own standards to govern the development and implementation of training and testing for facial comparison specialists. Underpinned by the activities of the Australian government and research community, Australia is leading the way in terms of progressing the field of facial comparison. 


\section{References}

Anastasi, J.S. \& Rhodes, M.G. (2006). Evidence for an own-age bias in face recognition. North American Journal of Psychology, 8, 237-253.

Australian Government (2012). National Identity Security Strategy: Statement of Biometric Interoperability Capability Requirements. Attorney Generals' Department. https://www.ag.gov.au/RightsAndProtections/IdentitySecurity/Documents/state ment-of-biometric-interoperability-capability-requirements.pdf.

Burton, A.M., Wilson, S., Cowan, M. \& Bruce, V. (1999). Face Recognition in Poor-Quality Video: Evidence from Security Surveillance. Psychological Science, 10, 243-248.

Byatt, C. \& Rhodes, G. (2004). Identification of own-race and other-race faces: Implications for the representation of race in face space. Psychonomic Bulletin and Review, 11, 735741.

Calic, D. (2012). From the laboratory to the real world: evaluating the impact of impostors, expertise and individual differences on human face matching performance. PhD Thesis. University of Adelaide, Adelaide.

Canberra Institute of Technology (2017). Certificate IV in Biometrics, https://cit.edu.au/courses/science_environment/biometrics

Connor, S. (2014). Passport officers no better than untrained amateurs at recognising faces, study finds. The Independent, UK. http://www.independent.co.uk/travel/news-andadvice/ passport-officers-no-better-than-untrained-amateurs-at-recognising-facesstudy-finds-9676869.html.

Dror, I.E. \& Rosenthal, R. (2008). Meta-analytically quantifying the reliability and bias ability of forensic experts. Journal of Forensic Sciences, 53(4), 900-903.

Edmond, G. (2010). Actual innocents: Law's limitations and their implications for forensic science and medicine. Plenary Address at the International Symposium on the Forensic Sciences (ANZFSS'10), 5-9 September, Sydney, Australia.

Edmond, G., Biber, K., Kemp, R. \& Porter G. (2009). Law's Looking Glass: Expert Identification Evidence Derived from Photographic and Video Images. Current Issues in Criminal Justice, 20, 337-377.

Edmond, G., Found, B., Martire, K., Ballantyne, K., Hamer, D., Searston, R., Thompson, M., Cunliffe, E., Kemp, R., San Roque, M., Tangen, J., Dioso-Villa, R., Ligertwood, A., Hibbert, D., White, D., Ribeiro, G., Porter, G., Towler, A. \& Roberts, A. (2016) Model forensic science, Australian Journal of Forensic Sciences, 48:5, 496-537. 
FISWG/Facial Identification Scientific Working Group (2010, November 18). Guidelines and Recommendations for Facial Comparison Training to Competency. Retrieved 26 November 2010, from http:/ / www.fiswg.org.

Heyer, R. (2013). Understanding One-to-Many Unfamiliar Face Matching in the Operational Context: The Impact of Candidate List Size, Expertise, and Decision Aids on the Performance of Facial Recognition System Users. PhD Thesis. University of Adelaide, Adelaide.

ICAO (2003). Doc 9303, Part 1, Machine Readable Passports, Fifth Edition. International Civil Aviation Organization.

Kenya High Commission (2017). Passports. http://www.kenya.asn.au/?page_id=13211.

Moss, P. (2015). An Australian facial training standard. Paper presented at the Unfamiliar Face Identification Group (UFIG) Meeting, 09-11 February, Sydney.

Moss, P. (2016). Facial Identification Scientific Working Group (FISWG) and Facial Aptitude Competency and Error Testing (FACET) group update. Paper presented at the Unfamiliar Face Identification Group (UFIG) Meeting, 8-10 February, Sydney.

NIST (2017). Organization of Scientific Area Committees: An Overview. http://www.nist.gov/forensics/osac/index.cfm.

Reynolds, M.E. \& Baldwin, D.P. (2010). Current status of the scientific working group on bloodstain pattern analysis (SWGSTAIN). Paper presented at the International Symposium on the Forensic Sciences (ANZFSS'10), 5-9 September, Sydney, Australia.

Semmer, C.,Ma-Wyatt, A., Semmler, C., Heyer, R., \& MacLeod, V. (2012). Improving Human Operator Capability for Face Biometric Identification: Final Report. Adelaide: University of Adelaide.

Tullberg, C. \& Owens, B. (2016). Victoria Police iFACE Facial Recognition System - a law enforcement end user's perspective. Paper presented at the Unfamiliar Face Identification Group (UFIG) Meeting, 8-10 February, Sydney.

White, D., Kemp, R., Jenkins, R., Matheson, M., \& Burton, A. (2014). Passport Officers' Errors in Face Matching. PLoS ONE. 9, e103510. doi:10.1371/journal. pone.0103510

Williams, P., Lynch, M. \& Chadwick, D. (2013). Current biometric requirements: a perspective from the Facial Biometrics Centre of Expertise and the Department of Immigration and Citizenship. Presented at Biometrics Institute Technology Showcase, 26 November, Canberra.

Wright, D.B. \& Sladden, B. (2003). An own gender bias and the importance of hair in face recognition. Acta Psychologica, 114, 101-114. 


\section{Appendix A: Survey}
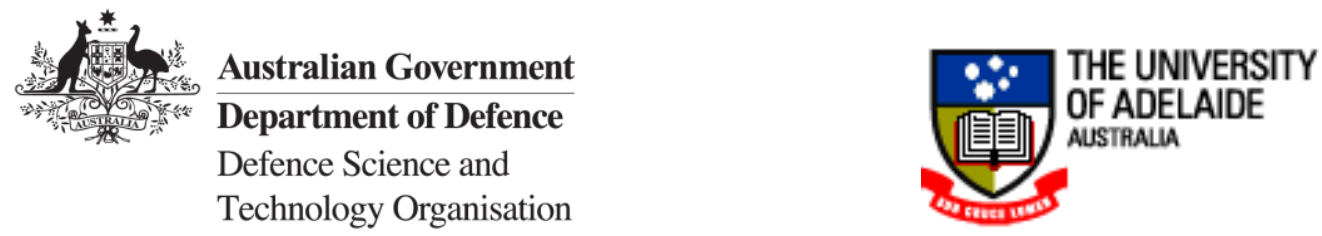

\section{HUMAN OPERATOR CAPABILITY PROJECT \\ PARTICIPANT SURVEY}

The Human Operator Capability Project addresses the need for improving the accuracy and efficiency of the identity verification tasks carried out by national security agencies. It aims to assess the key behavioural factors associated with accurate facial identification decisions. We recognise the fact that the types of tasks that human operators carry out in verifying the identity of individuals may vary considerably across agencies. This survey is designed to ensure that the data gathered during the course of the Human Operator Capability Project and beyond are of maximum relevance to the agencies contributing to the project. This will in part be achieved by gathering general information regarding operational contexts and personal characteristics from participants in the trials through this survey.

This survey covers demographic information, training and experience, facial identification techniques, the use of facial recognition systems in operational duties, and reporting of facial identification results. The results of this survey will help to place the results of the trials into context for each agency. The results will also help to plan for further research by providing information that can be used to refine the tasks used in operator trials, identify issues in the use of facial recognition systems, training needs and future support for operators in their duties.

This research has been approved by the University of Adelaide's School of Psychology Human Research Ethics Subcommittee Code 10/79.

In order for us to be able to cross reference the answers you provide on the following survey, while keeping them anonymous, we require you to please enter your name and indicate which agency you work for below. Once this survey has been received by our research team, this page will be separated from the rest of the survey and the bar code below will then become your identifier for the remainder of the project.

Your Name:

Your Agency:

Barcode:

Please place your completed survey in the provided envelope and bring it along to your data collection session. 


\title{
Some definitions
}

Throughout the survey we use several general terms to describe the tasks and systems that may be different to the terms normally used by you and your agency. To ensure that the information that you give us is accurate, we have defined these terms here:

- Human operator: a person who makes facial identification decisions.

- Facial identification: any process whereby a decision is made regarding the identity of a person using their face as the primary source of information and comparing their face to another face (whether an image or a physically present person).

- Other forensic identification: this includes things such as fingerprint analysis, document examination or verification, and crime scene analysis.

- Facial recognition system: a computer system that uses a mathematical model or algorithm to automatically identify or verify a person.

- Trials: the data collection process that will be occurring during August/September as part of the Human Operator Capability Project (includes a series of computer-based facial recognition tasks as well as individual differences or psychological testing).

\section{If you run out of room while completing the survey}

While completing the survey if you run out of room, please continue your answers in Part 6 for general questions and Part 7 for training and experience questions. Please be sure to write the number of the question which you are continuing so that we have a reference point for your answer.

\section{If you have any questions while completing the survey}

Please feel free to contact me should you have any questions while completing the survey (please note that mobile phone will be the best form of contact from 16 August 2010).

\author{
Rebecca Heyer \\ rebecca.heyer@dsto.defence.gov.au \\ $X X X X X X X X X X$ \\ $X X X X X X X X X X$
}

Thank you for taking the time to complete the survey and we look forward to meeting you at the experimental sessions. 


\section{Part 1. Demographics}

Previous research has found that some demographic variables, particularly age, gender and ethnicity, can have an impact on face matching ability. In addition, questions about correction of vision are routinely asked when computer-based tasks are to be completed, such as those that you may participate in during August/September. Please answer the following demographic questions.

1. Please indicate your age (in years) [free text]

2. Are you male or female? [drop down menu for selection]

- Male

- Female

3. What is the highest level of education you have attained? [drop down menu for selection]

- University Honours Level or Higher

- University Bachelor Degree

- Post-Secondary (such as Cert1, CertIV, Diploma)

- Secondary Schooling

- Other, please specify [free text]

4. Please list your qualifications, including majors [free text]

5. Ethnicity [drop down menu with selection]

- Caucasian

- Asian

- African

- Other, please specify [free text]

6. Were you born in Australia? [drop down menu for selection]

- Yes $\rightarrow$ go to Question 8

- No

7. If no, how long have you been in Australia? [drop down menu for selection]

- 0-5 years

- 6-10 years

- 11-15 years

- 16-20 years

- 20+ years

8. Do you wear glasses or contact lenses to correct your vision? [drop down menu for selection]

- Yes

- $\mathrm{No} \rightarrow$ go to Question 10 
9. What do you primarily wear glasses for? [drop down menu for selection]

- Using computer

- Reading

- Driving

- Day-to-day activities

- Other, please specify [free text]

10. Have you participated in any facial recognition research activities before?

- Yes

- No $\rightarrow$ go to Question 12

- Unsure

11. If yes or unsure, please provide some details (i.e., when, with who, what was the research about etc.) [free text] 


\section{Part 2. Your Current Job, Training and Other Experience}

Anecdotal evidence suggests that the training and experience backgrounds of individual operators varies considerably across national security agencies within Australia. This set of questions is designed to help us confirm this variability, while assisting us to understand your performance in the trials you may participate in during August/September.

12. What agency do you currently work for? [drop down menu for selection])

Response fields deleted for confidentiality reasons

13. What is your current level or rank? [drop down menu for selection])

Response fields deleted for confidentiality reasons

14. What selection process did you go through to obtain your current position? [drop down menu for selection, please select as many as are relevant]

- Interview

- Assessment centre

- Psychological testing

- Work samples

- Referee reports

- Other, please list [free text]

15. Have you attended, or are you currently attending, any training courses that are related to facial or other forensic identification? [drop down menu for selection]

- Yes

- $\quad$ No $\rightarrow$ go to Question 17

16. Please list training courses you have attended, or are currently attending, that directly relate to facial or other forensic identification

- Name of the training or course [free text]

- Year attended [drop down menu for selection]

- Years for selection

- Duration of the training [drop down menu for selection]

- Less than one day

- 1 day

- 2 days

- 3 days

- 4 days

- 5 days

- 1-2 weeks

- Greater than 2 weeks 
- Was the course assessed (i.e., did you have to complete some form of assessment)?

- Yes

- No

- Unsure

- Briefly describe the training [free text]

- Please rate how useful the training has been for you? [select one of the following]

- 1 (not useful)

$-2$

$-3$

$-4$

- 5 (very useful)

- Are there any other comments you would like to make about this training? [free text]

Additional training courses can be added.

17. Please list all work experience you have had starting with your current position and also including previous positions which you believe in some way relate to your current position, or the facial or forensic identification area in general

- Job Title [free text]

- Agency [drop down menu for selection]

- Response fields deleted for confidentiality reasons

- Duration of employment [drop down menu for selection]

- Less than 6 months

- 6 - 12 months

- $1-5$ years

- 6-10 years

- Greater than 10 years

- Brief description of duties [free text]

18. Do you work shifts? [drop down menu for selection]

- Yes

- $\quad$ No $\rightarrow$ go to Question 22

19. How many shifts do you work, on average per week? [drop down menu for selection]

- 1

- 2

- 3

- 4

- 5

- 6

- 7

- More than 7 


\section{UNCLASSIFIED}

[DST-Group-GD-XXXX]

20. What is the duration of your shifts? [drop down menu for selection]

- Less than 5 hours

- 6-8 hours

- 9-12 hours

- Greater than 12 hours

21. What hours do your shifts generally fall between? [a drop down menu for selection (to select start and finish times, or an option to select variable shifts, and write comments]

- Start: All times on the hour

- Finish: All times on the hour

- Variable shifts

- Other, please explain [free text] 


\section{Part 3. Your Facial Identification Experience}

Facial identification refers to any process whereby a decision is made regarding the identity of a person using their face as the primary source of information (comparing their face to another or many other faces, whether an image or a physically present person). The types of facial identification tasks that human operators carry out may vary considerably across agencies. Some operators spend the vast majority of their days engaged in facial identification tasks, while for others facial identification tasks are a very minor part of their regular duties. This set of questions is designed to get an understanding of how often you perform facial identification tasks, what kinds of tasks you perform and the techniques you employ.

22. What percentage of time, on average, do you spend performing facial identification tasks in your everyday work? [drop down menu for selection]

- $1-10 \%$

- $11-20 \%$

- $21-30 \%$

- $31-40 \%$

- $41-50 \%$

- $51-60 \%$

- $61-70 \%$

- $71-80 \%$

- $81-90 \%$

- $91-100 \%$

- Comment [optional, free text]

23. What kinds of facial identification tasks do you perform? [drop down menu, can select as many as are relevant]

- One-to-one image (comparing one image with another image)

- One-to-one live (comparing one image with a physically present person)

- One-to-many image (comparing one image with many other images)

- One-to-many live (comparing one physically present person with many images)

- Many-to-many (comparing many images with many other images)

- Many-to-many live (comparing many physically present people with many other images)

- Other, please list [free text]

24. Which task makes up the largest proportion of your workload in the broad area of facial identification? [drop down menu, can select one only]

- One-to-one image (comparing one image with another image)

- One-to-one live (comparing one image with a physically present person)

- One-to-many image (comparing one image with many other images)

- One-to-many live (comparing one physically present person with many images)

- Many-to-many (comparing many images with many other images)

- Many-to-many live (comparing many physically present people with many other images)

- Other, please list [free text] 
[DST-Group-GD-XXXX]

25. On the image below, using numbers, please label those areas of the face you most commonly use when making facial identification decisions. Please start with the number 1 for the part of the face you use the most and continue until you have labeled all of those areas of the face that you use. Please use the comments field to provide any explanatory comments.

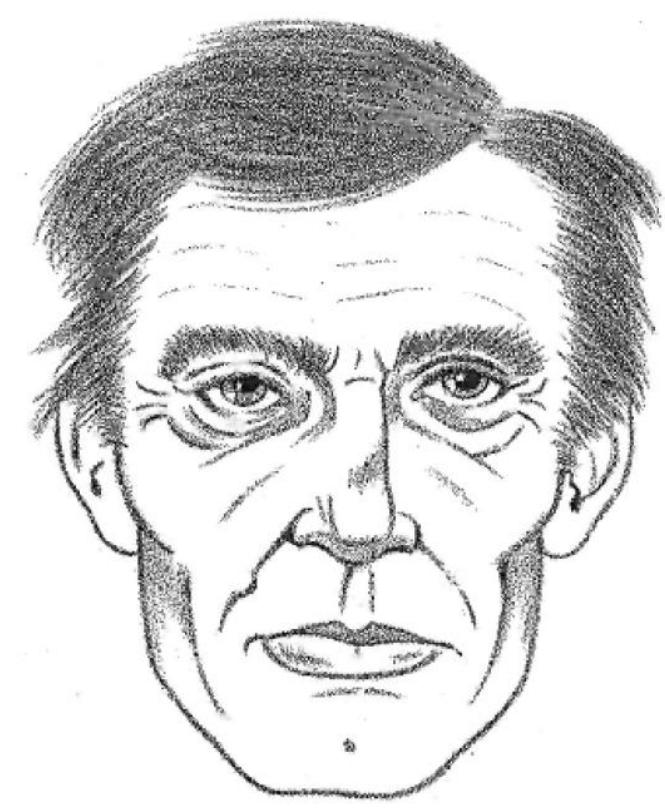

26. When performing facial identification tasks how important are the following features in guiding your decision?

a. Eye colour [select one of the following]

- 1 (not useful)

- 2

- 3

- 4

- 5 (very useful)

b. Hair colour [select one of the following]

- 1 (not useful)

$-2$

$-3$

$-4$

- 5 (very useful)

c. Hair style [select one of the following]

- 1 (not useful)

- 2

- 3

$-4$

- 5 (very useful) 
d. Hair line [select one of the following]

- 1 (not useful)

$-2$

$-3$

$-4$

- 5 (very useful)

e. Facial hair (grown/shaved) [select one of the following]

- 1 (not useful)

$-2$

$-3$

$-4$

- 5 (very useful)

f. Scars/marks [select one of the following]

- 1 (not useful)

$-2$

- 3

$-4$

- 5 (very useful)

g. Freckles/moles [select one of the following]

- 1 (not useful)

$-2$

- 3

$-4$

- 5 (very useful)

h. Wrinkles/creases [select one of the following]

- 1 (not useful)

- 2

$-3$

- 4

- 5 (very useful)

i. Tattoos [select one of the following]

- 1 (not useful)

$-2$

$-3$

- 4

- 5 (very useful)

j. Piercings [select one of the following]

- 1 (not useful)

- 2

- 3

- 4

- 5 (very useful) 
[DST-Group-GD-XXXX]

27. How many facial identification decisions, on average, do you believe you complete per day? [drop down menu for selection]

- $1-10$

- $11-20$

- $21-30$

- $31-40$

- $41-50$

- $51-100$

- Greater than 100

28. Do you have time limits or pressures when performing facial identification tasks? [drop down menu for selection]

- Yes

- No

- Please explain [free text]

29. Do you have a quota to meet when performing facial identification tasks? [drop down menu for selection]

- Yes

- No $\rightarrow$ go to Question 31

- Unsure (please explain [free text])

30. If yes, what is the quota? [free text]

31. Is your facial identification decision final? [drop down menu for selection]

- Yes

- No

- Comment [optional, free text]

32. Can you seek the advice of someone else when making a facial identification decision? [drop down menu for selection]

- Yes

- No $\rightarrow$ go to Question 34

- Comment [optional, free text]

33. How often would you seek advice when making a facial identification decision? [drop down menu for selection]

- Several times a day

- Once or twice per week

- Once or twice per month

- Less than once or twice per month

- Please explain [free text]

34. Can you defer a facial identification decision to another person? [drop down menu for selection]

- Yes

- No $\rightarrow$ go to Question 36

- Comment [optional, free text] 
35. How often would you defer a facial identification decision to another person? [drop down menu for selection]

- Several times a day

- Once or twice per week

- Once or twice per month

- Less than once or twice per month

- Please explain [free text]

36. What software do you have available to you to assist you in making facial identification decisions? [free text to list]

37. What other decision aids (such as reference texts) do you have to assist you in making facial identification decisions? [free text to list]

38. What colour images do you commonly use when making facial identification decisions? [drop down menu for selection]

- Black and white

- Colour

- Combination

- Other, please list [free text]

39. Which colour do you find is easier to work with? [drop down menu for selection]

- Black and white

- Colour

- Either, it doesn't matter

- Other, please list [free text]

40. What kinds of images do you use when making facial identification decisions? [drop down menu for selection, select as many as you like]

- A combination of moving/video and still images

- Just moving/video $\rightarrow$ go to Question 42

- Just still images $\rightarrow$ go to Question 42

- Other, please list [free text]

41. If more than one kind of image is used, which do you use more often? [drop down menu for selection]

- Moving/video

- Still

- Other, please list [free text]

42. Do you have the ability to manipulate an image to improve it during examination? [drop down menu for selection]

- Yes

- No $\rightarrow$ go to Question 44

- Comment [optional, free text]

43. Please explain what image manipulation techniques you use [free text] 
44. What level of quality are the images you use for facial identification tasks? [drop down menu for selection]

- Very high quality (e.g., 4-6 megapixel digital images)

- High quality (e.g., passport images)

- Low quality (e.g., CCTV footage)

- Very low quality (e.g., photocopies or faxes of images or very small digital images)

- Variable quality

45. Do you think using higher quality images would improve your accuracy? [drop down menu for selection]

- Yes

- No

- Comment [optional, free text]

46. Do you think using higher quality images would enable you to more quickly make a comparison/decision? [drop down menu for selection]

- Yes

- No

- Comment [optional, free text]

47. For each of the following decision scenarios please rate what the impact of your decision would be on the scale provided.

a. Scenario 1: You state that two faces are NOT a match (they belong to different people), but the faces really ARE a match (it actually is the same person) [rating scale from negative to positive outcome, also the option to select not applicable, and free text to provide optional explanation]

- 1 (negative impact - this is not a good outcome, an outcome to be avoided)

- 2

- 3

- 4

- 5 (positive impact - this is a good outcome, an outcome we aim for)

- Not applicable (you do not perform tasks such as this in your current job)

- Please explain the impact of your decision [optional, free text]

b. Scenario 2: You state that two faces are NOT a match (they belong to different people) and you are correct, the faces really do NOT match (it really isn't the same person) [rating scale from negative to positive outcome, also the option to select not applicable, and free text to provide optional explanation]

- 1 (negative impact - this is not a good outcome, an outcome to be avoided)

- 2

- 3

- 4

- 5 (positive impact - this is a good outcome, an outcome we aim for)

- Please explain the impact of your decision [optional, free text] 
c. Scenario 3: You state that the faces ARE a match (it is the same person), but this is not the case, they really are NOT a match (they are actually two different people) [rating scale from negative to positive outcome, also the option to select not applicable, and free text to provide optional explanation]

- 1 (negative impact - this is not a good outcome, an outcome to be avoided)

- 2

- 3

- 4

- 5 (positive impact - this is a good outcome, an outcome we aim for)

- Not applicable (you do not perform tasks such as this in your current job)

- Please explain the impact of your decision [optional, free text]

d. Scenario 4: You state that the faces ARE a match (it is the same person), and you are correct, they really ARE a match (it really is the same person) [rating scale from negative to positive outcome, also the option to select not applicable, and free text to provide optional explanation]

- 1 (negative impact - this is not a good outcome, an outcome to be avoided)

- 2

- 3

- 4

- 5 (positive impact - this is a good outcome, an outcome we aim for)

- Not applicable (you do not perform tasks such as this in your current job)

- Please explain the impact of your decision [optional, free text]

48. How accurate do you think you are when making identification decisions?

- 1 extremely inaccurate

- 2

- 3

- 4

- 5 extremely accurate

- Comment [optional, free text]

49. On average, how mentally demanding do you find facial identification tasks? [drop down menu for selection]

- 1 Very mentally demanding

- 2

- 3

- 4

- 5 Not at all mentally demanding

- Comment [optional, free text]

50. On average, how often do you feel the need to take a rest from your facial identification duties? [drop down menu for selection]

- 1 Very often (every 10 minutes or so)

- 2

- 3

- 4

- 5 Not often at all (once a day)

- Comment [optional, free text] 
51. How do the following factors effect your facial identification ability?

a. If the person you are trying to identify is from a different ethnicity to you [drop down menu for selection]

- 1 Positive effect (I find facial identification easier when dealing with other ethnicities)

○ 2

- 3 Nil effect (My facial identification ability is the same with all ethnicities)

○ 4

- 5 Negative effect (I find facial identification with some ethnicities quite difficult)

- Comment [optional, free text]

- If you answered 4 or 5 , which ethnicities do you find most challenging? [free text]

b. If the person you are trying to identify is a lot younger or a lot older than you [drop down menu for selection]

- 1 Positive effect (I find facial identification easier when dealing with a range of age groups)

○ 2

- 3 Nil effect (My facial identification ability is the same with all age groups)

○ 4

- 5 Negative effect (I find facial identification with some age groups quite difficult)

- Comment [optional, free text]

- If you answered 4 or 5 , which age groups do you find most challenging? [free text]

c. If the person you are trying to identify is from the opposite gender [drop down menu for selection]

- 1 Positive effect (I find facial identification easier when dealing with the opposite gender to me)

$\circ 2$

- 3 Nil effect (My facial identification ability is the same with both males and females)

○ 4

- 5 Negative effect (I find facial identification with the opposite gender quite difficult)

- Comment [optional, free text]

d. If the imagery from which you are trying to identify is of poor quality [drop down menu for selection]

- 1 Positive effect (I find facial identification easier when dealing with poor quality imagery)

○ 2

- 3 Nil effect (My facial identification ability is the same regardless of the quality of the imagery)

- 4

- 5 Negative effect (I find facial identification with poor quality imagery quite difficult)

- Comment [optional, free text]

- If you answered 4 or 5 , which is the worst imagery to work with? [free text] 
e. If there are appearance changes/differences between an image of a person and another image of them or their presentation in person [drop down menu for selection]

- 1 Positive effect (I find facial identification easier when there are appearance changes/differences between an image of a person and another image of them or their presentation in person)

○ 2

- 3 Nil effect (My facial identification ability is the same regardless of whether there are appearance changes/differences between an image of a person and another image of them or their presentation in person)

○ 4

- 5 Negative effect (I find facial identification more difficult when there are appearance changes/differences between an image of a person and another image of them or their presentation in person)

- Comment [optional, free text]

- If you answered 4 or 5 , which appearance changes do you find most challenging? [free text]

52. What things do you feel would assist you to develop your facial identification skills? [drop down menu, can select as many as are relevant]

- Refresher of previous training

- New training

- More on the job experience

- Secondments to other agencies engaged in similar work

- Networking opportunities with people in your field of work

- Computer imaging tools to help compare images/subject and images

- Other, please list [free text] 


\section{Part 4. Facial Recognition System}

Facial recognition systems use an algorithm to automatically identify or verify a person's identity. Many Australian government agencies have implemented facial recognition systems to replace, or to complement, their manual processes. This set of questions is designed to get an idea of how many agencies are using facial recognition systems, in what ways they are being used, and in what ways their use may be improved.

53. Do you use a facial recognition system to assist you in your duties? [drop down menu for selection]

- Yes

- No $\rightarrow$ go to Question 55

- Unsure $\rightarrow$ go to Question 55

54. Do you use a facial recognition system all the time or only when required?

- All the time $\rightarrow$ go to Question 56

- Only when required $\rightarrow$ go to Question 56

- Other, please explain [free text] $\rightarrow$ go to Question 56

55. Would you like to have the option to use a facial recognition system to assist you in your duties? [drop down menu for selection]

- Yes $\rightarrow$ go to Question 73

- No $\rightarrow$ go to Question 73

- Unsure $\rightarrow$ go to Question 73

56. Were you formally trained to use the facial recognition system? [drop down menu for selection]

- Yes

- No $\rightarrow$ go to Question 59

- Unsure, please explain/add comment [free text] $\rightarrow$ go to Question 59

57. If you did not provide details in the earlier training questions, please provide details of the training here [free text]

- Name of the training or course [free text]

- Year attended [drop down menu for selection]

- List of years from 2010 to 1960 ?

- Duration of the training [drop down menu for selection]

- Less than one day

- 1 day

- 2 days

- 3 days

- 4 days

- 5 days

- 1-2 weeks

- Greater than 2 weeks 
- Was the course assessed (i.e., did you have to complete some form of assessment such as an essay or exam)?

- Yes

- No

- Unsure

- Briefly describe the training [free text]

58. How useful was the training? [drop down menu for selection]

- 1 (not useful)

- 2

- 3

- 4

- 5 (very useful)

59. What decision aids does your system provide? [drop down menu for selection, select all that apply]

- Match scores presented with images

- Images presented in match score order

- Highlighting used to signify highest matching image/s

- Overlay tools (the ability to overlay two images on top of one another)

- Facial mapping tools (the ability to conduct anthropometric and/or morphological analysis of faces, e.g., measurements)

- Options to see other related images

- Option to refer/defer a match in progress to someone else electronically

- Option to create a suspected, but not confirmed match (i.e., the two faces are most likely from the same person)

- Soft biometrics (biographical details)

- Other, please list [free text]

60. Where relevant, how useful do you find the following decision aids?

a. Scores, percentages or ratings presented with images [select one of the following]

- 1 (not very useful)

$-2$

$-3$

$-4$

- 5 (very useful)

- Not Applicable (not available on the system I use)

b. Images presented in match score order [select one of the following]

- 1 (not very useful)

$-2$

$-3$

$-4$

- 5 (very useful)

- Not Applicable (not available on the system I use) 
c. Highlighting used to signify highest matching image/s [select one of the following] - 1 (not very useful)

$-2$

$-3$

$-4$

- 5 (very useful)

- Not Applicable (not available on the system I use)

d. Overlay tools [select one of the following]

- 1 (not very useful)

$-2$

$-3$

$-4$

- 5 (very useful)

- Not Applicable (not available on the system I use)

e. Facial mapping tools [select one of the following]

- 1 (not very useful)

$-2$

- 3

$-4$

- 5 (very useful)

- Not Applicable (not available on the system I use)

f. Options to see other related images [select one of the following]

- 1 (not very useful)

$-2$

$-3$

$-4$

- 5 (very useful)

- Not Applicable (not available on the system I use)

g. Option to refer/defer a match in progress to someone else electronically [select one of the following]

- 1 (not very useful)

$-2$

$-3$

$-4$

- 5 (very useful)

- Not Applicable (not available on the system I use)

h. Option to create a suspected, but not confirmed match [select one of the following]

- 1 (not very useful)

$-2$

- 3

$-4$

- 5 (very useful)

- Not Applicable (not available on the system I use) 
i. Soft biometrics (biographical details) [select one of the following]

- 1 (not very useful)

$-2$

$-3$

$-4$

- 5 (very useful)

- Not Applicable (not available on the system I use)

j. Other, please list [free text]

61. If performing one-to-many tasks, what size is the gallery or candidate list? [drop down menu for selection]

- 1-5 images

- 6-10 images

- 11-20 images

- 21-30 images

- 31-50 images

- 51-70 images

- 71-100 images

- Greater than 100 images

- Variable

- If so, please provide a range/comment [free text]

- Not applicable

62. How accurate do you think the automated facial recognition system is? [drop down menu for selection]

- 1 extremely inaccurate

- 2

- 3

- 4

- 5 extremely accurate

- Comment [optional, free text]

63. Have you ever revised your initial decision because of what the facial recognition system indicated? [drop down menu for selection]

- Yes

- No $\rightarrow$ go to Question 64

- Comment [optional, free text] 
64. Please explain what happened when you revised your decision [free text]

65. Is there an option to switch the facial recognition system off or bypass the system? [drop down menu for selection]

- Yes

- No $\rightarrow$ go to Question 67

66. Please explain how the facial recognition system can be switched off or bypassed [free text]

67. Are multiple images of a person of interest, visa applicant or traveller used in your facial recognition system, or is there just a single image of each person only? [drop down menu for selection]

- Single image

- Multiple images

- Combination (some people have multiple images in the database, others just have a single image)

- Unsure

68. How often is the user interface of the facial recognition system updated/changed? [drop down menu for selection]

- Weekly

- Monthly

- 6-monthly

- Yearly

- Every couple of years

- Unsure

69. Do you think the user interface of your system could be improved? [drop down menu for selection]

- Yes

- No $\rightarrow$ go to Question 71

- Unsure

70. What aspects of the user interface could be improved? [free text to add explanation]

71. Do you have the ability to customise your user interface? [drop down menu for selection]

- Yes

- $\quad$ No $\rightarrow$ go to Question 73

72. Please explain which aspects of the user interface you can, or have, customised yourself? [optional, free text] 
73. What size screen do you use to perform facial identification tasks? [drop down menu for selection]

- Less than 3"

- $3-4$ " (iPhone/iPod Touch)

- $5-8$ "

- 9-10" (iPad/netbook)

- 11-14" (small laptop or netbook)

- $15^{\prime \prime}$

- $17^{\prime \prime}$

- $19^{\prime \prime}$

- $21^{\prime \prime}$

- $23^{\prime \prime}$

- $25^{\prime \prime}$

- 27"

- Greater than 27"

- Unsure

- Do not use a computer screen for facial identification tasks $\rightarrow$ go to Question 79

- Other, please explain [free text]

74. Is the screen size adequate?

- Yes $\rightarrow$ go to Question 76

- No

- $\quad$ Unsure $\rightarrow$ go to Question 76

75. If no, what size would you prefer?

- Less than 3"

- 3-4" (iPhone/iPod Touch)

- $5-8^{\prime \prime}$

- 9-10" (iPad/netbook)

- 11-14" (small laptop or netbook)

- $15^{\prime \prime}$

- $17^{\prime \prime}$

- $19^{\prime \prime}$

- $21^{\prime \prime}$

- $23^{\prime \prime}$

- $25^{\prime \prime}$

- 27"

- Greater than 27"

76. Do you use more than one screen to perform facial identification tasks? [drop down menu for selection]

- Yes

- $\quad$ No $\rightarrow$ go to Question 79 
[DST-Group-GD-XXXX]

77. How many screens do you use for facial identification tasks? [drop down menu for selection]

- 2

- 3

- 4

- 5 or more

- Please explain [optional, free text]

78. What sizes are the screens? [drop down menu for selection, option to select two different values or two or more of the same values]

- Less than $3^{\prime \prime}$

- 3-4" (iPhone/iPod Touch)

- $5-8^{\prime \prime}$

- 9-10" (iPad/netbook)

- 11-14" (small laptop or netbook)

- $15^{\prime \prime}$

- $17^{\prime \prime}$

- $19^{\prime \prime}$

- $21^{\prime \prime}$

- $23^{\prime \prime}$

- $25^{\prime \prime}$

- $27^{\prime \prime}$

- Greater than 27"

- Other (please explain) [free text]

79. Would you like to use more than one screen for facial identification tasks? [drop down menu for selection]

- Yes

- No

- Unsure 


\section{Part 5. Reporting of Decisions}

The way that a facial identification decision is reported varies according to the operational reason the identification is made. We are interested in the ways in which different agencies, and even different branches within agencies, report their decisions. This set of questions is designed to capture that information.

80. Please describe how you report your facial identification decision [drop down menu for selection]

- Verbally (involving no formal electronic or paper-based records)

- Electronically using a formal agency template

- Electronically using informal means (e.g., non-standard email, instant messaging)

- Paper-based using a formal agency template

- Paper-based using informal means (e.g., non-standard format, format varies)

- A combination of the above

- Other (please explain) [free text]

81. What details are included in the report? [drop down menu for selection, select as many as are relevant]

- Your name or other identifier

- Background details about the person of interest or case

- Copies of the images about which you have made a decision

- Match scores or other metrics from a facial recognition system

- Results of facial mapping or overlay analysis

- Details about the process you went through to make the decision

- Details about the decision aids you used to make your decision (e.g., reference books, software packages, consultation of others)

- Details about the people you may have consulted in the process of making your decision

- Other (please explain) [free text]

82. Who verifies your facial identification decision? [drop down menu for selection, select as many as are relevant]

- A peer/work colleague at your level

- Several peer/work colleagues at your level

- One person at a higher level than you (e.g., supervisor)

- Several people at a higher level than you

- My decisions are not formally verified

- Other (please explain) [free text] 
[DST-Group-GD-XXXX]

\section{UNCLASSIFIED}

\section{Part 6. Other Comments}

83. Are there any other comments you would like to make? [free text] 


\section{DISTRIBUTION LIST}

Profiling the Facial Comparison Practitioner in Australia

Rebecca Heyer, Veneta MacLeod, Laura Carter, Carolyn Semmler \& Anna Ma-Wyatt

\section{DEFENCE}

\section{Task Sponsor}

Chair, Facial Biometrics Centre of Expertise (Attorney General's 1 Department)

\section{S\&T Program}

Chief of NSID 1

Research Leader Intelligence Analytics $\quad 1$

Program Leader National Security 1

Head Biometrics, Robin Nicholson $\quad 1$

Rebecca Heyer, Veneta MacLeod, Laura Carter, Carolyn Semmler \& Anna 1 Ma-Wyatt

\section{Universities and Colleges}

Australian Defence Force Academy

Hargrave Library, Monash University

\section{INTERNATIONAL DEFENCE INFORMATION CENTRES}

US Defense Technical Information Center

UK Dstl Knowledge Services

Canada Defence Research Directorate R\&D Knowledge \& Information

Management (DRDKIM)

NZ Defence Information Centre 


\section{DEFENCE SCIENCE AND TECHNOLOGY GROUP DOCUMENT CONTROL DATA}

\begin{abstract}
2. TITLE
Profiling the Facial Comparison Practitioner in Australia
\end{abstract}

3. SECURITY CLASSIFICATION (FOR UNCLASSIFIED REPORTS THAT ARE LIMITED RELEASE USE (U/L) NEXT TO DOCUMENT CLASSIFICATION)

$\begin{array}{ll}\text { Document } & (\mathrm{U}) \\ \text { Title } & (\mathrm{U}) \\ \text { Abstract } & (\mathrm{U})\end{array}$

5. CORPORATE AUTHOR

Defence Science and Technology Group

[Insert the site mailing address, found at: http://intranet.dsto.defence.gov.au/about/sites/]

Rebecca Heyer, Veneta MacLeod, Laura Carter, Carolyn Semmler \& Anna Ma-Wyatt

\begin{tabular}{|l|l|}
\hline $\begin{array}{l}\text { 6a. DST Group NUMBER } \\
\text { DST-Group-GD-XXXX }\end{array}$ & $\begin{array}{l}\text { 6b. AR NUMBER } \\
\text { AR-XXX-XXX }\end{array}$ \\
\hline $\begin{array}{l}\text { 8. Objective ID } \\
\text { [insert ID] }\end{array}$ & $\begin{array}{l}\text { 9. TASK NUMBER } \\
07 / 029\end{array}$ \\
\hline & \\
\hline 13. DOWNGRADING/DELIMITING INSTRUCTIONS
\end{tabular}

6c. TYPE OF REPORT

7. DOCUMENT DATE

General Document

February 2017

10. TASK SPONSOR

Chair, Facial Biometrics Centre of Expertise (Attorney General's Department)

\begin{tabular}{|l|l}
\hline 13. DOWNGRADING/DELIMITING INSTRUCTIONS & $\begin{array}{l}\text { 14. RELEASE AUTHORITY } \\
\text { Chief, National Security \& Intelligence, Surveillance and } \\
\text { Reconnaissance Division }\end{array}$
\end{tabular}

15. SECONDARY RELEASE STATEMENT OF THIS DOCUMENT

Approved for public release.

OVERSEAS ENQUIRIES OUTSIDE STATED LIMITATIONS SHOULD BE REFERRED THROUGH DOCUMENT EXCHANGE, PO BOX 1500, EDINBURGH, SA 5111 16. DELIBERATE ANNOUNCEMENT

Approved for public release.

\section{CITATION IN OTHER DOCUMENTS Yes}

\section{RESEARCH LIBRARY THESAURUS}

Face recognition, biometric identification, surveys

\section{ABSTRACT}

As part of a joint University of Adelaide-Defence Science and Technology Group project, known as the Human Operator Capability Project, a comprehensive survey of 149 facial comparison practitioners within Australian State and Federal Government agencies was conducted in late 2010. The survey collected data in a range of categories including: demographics, training and work history, facial comparison tools and techniques, attitudes to the facial comparison task and the use of facial recognition systems. This report outlines the key findings from the survey, including implications for the consideration of participating agencies at the time. An epilogue reflects on what has changed in the time since the survey was conducted. 